\title{
Recent advances in cerebral cavernous malformation research
}

\author{
Akhil Padarti, Jun Zhang \\ Department of Biomedical Sciences, Texas Tech University Health Science Center El Paso, El Paso, TX 79905, USA. \\ Correspondence to: Dr. Jun Zhang, Department of Biomedical Sciences, Texas Tech Udniversity Health Science Center, $5001 \mathrm{El}$ \\ Paso Drive, El Paso, El Paso, TX 79905, USA. E-mail: jun.zhang2000@gmail.com
}

How to cite this article: Padarti A, Zhang J. Recent advances in cerebral cavernous malformation research. Vesse/ P/us 2018;2:21. http://dx.doi.org/10.20517/2574-1209.2018.34

Received: 15 May 2018 First Decision: 23 Jul 2018 Revised: 1 Aug 2018 Accepted: 15 Aug 2018 Published: 28 Aug 2018

Science Editor: Aaron S. Dumont Copy Editor: Huan-Liang Wu Production Editor: Cai-Hong Wang

\begin{abstract}
Cerebral cavernous malformations (CCM) are manifested by microvascular lesions characterized by leaky endothelial cells with minimal intervening parenchyma predominantly in the central nervous system predisposed to hemorrhagic stroke, resulting in focal neurological defects. Till date, three proteins are implicated in this condition: CCM1 (KRIT1), CCM2 (MGC4607), and CCM3 (PDCD10). These multi-domain proteins form a protein complex via CCM2 that function as a docking site for the CCM signaling complex, which modulates many signaling pathways. Defects in the formation of this signaling complex have been shown to affect a wide range of cellular processes including cell-cell contact stability, vascular angiogenesis, oxidative damage protection and multiple biogenic events. In this review we provide an update on recent advances in structure and function of these CCM proteins, especially focusing on the signaling cascades involved in CCM pathogenesis and the resultant CCM cellular phenotypes in the past decade.
\end{abstract}

Keywords: Cerebral cavernous malformation, cerebral cavernous malformation signaling complex, angiogenesis, endothelial cells, cellular function, microvessel lesions, protein structure, function domain, motif

\section{INTRODUCTION}

Cerebral cavernous malformations (CCMs) are vessel dilatations within microvascular beds in the brain that are predisposed to hemorrhagic stroke. These microvascular malformations are present in $0.5 \%$ in the general population $^{[1]}$. These lesions are characterized by densely packed tortuous microvessels outlined with deficient interstitial brain parenchyma ${ }^{[2,3]}$, increasing the propensity of these vascular lesions for leakage ${ }^{[4]}$. These microvascular lesions are predominantly found in the central nervous system (CNS) but are also known to affect skin and liver. Although it is highly prevalent $t^{[1]}$, a vast majority (approximately $70 \%$ ) are asymptomatic ${ }^{[5]}$.

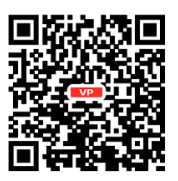


Even in patients affected by disease within the same family, there is a wide range of clinical presentations which are primarily determined by the number and size of lesions. This suggests that additional genetic modifiers or non-genetic factors may exist in the pathogenesis of the disease ${ }^{[6]}$. As of date, CCM1 (KRIT1) on chromosome 7q, CCM2 (MGC4607/OSM/Malcavernin) on chromosome 7p, and CCM3 (PDCD10/TFAR15) on chromosome $3 q$ are genes that are known to cause the familial form of CCM. It is estimated that 1 in 200 people harbor a potential mutation in one of three CCM genes and the frequency increases to 1 in 70 in the Hispanic population ${ }^{[7]}$. An epidemiological study showed that $94 \%$ of all familial forms and $57 \%$ of all sporadic forms of CCM result from mutations in one of these three genes ${ }^{[8]}$, raising a possibility that mutations in other genetic loci might exist ${ }^{[9,10]}$. Recently, many polymorphisms were found in patients with the sporadic form of the disease, further strengthening the argument that the presence of other genetic risk factors that can contribute to the sporadic cases of CCM is possible ${ }^{[1]}$. However, endeavors to identify novel CCM loci have so far failed. It was proposed that the lesions formed in the familial form through a "second hit" mutation while sporadic vascular lesions occurred due to somatic mutations in both alleles caused by mutagens, radiation, or other factors. However, the familial form has an increased propensity for lesions since only one functional allele is present. Therefore, the familial form characteristically develops neurological manifestations earlier with multiple brain lesions, while the sporadic form develops late neurological manifestation with solitary brain lesions ${ }^{[12,13]}$.

As mentioned earlier, at least one of these three genes $(C C M 1,2,3)$ is disrupted in most CCM cases in humans ${ }^{[14]}$. The three CCM proteins interact to form a protein complex ${ }^{[15-19]}$ which further interacts with other proteins ${ }^{[19-22]}$. This CCM protein complex, referred to as the CCM signaling complex (CSC) ${ }^{[19]}$, has affinity toward a wide range of ligands and such interactions are involved in cell adhesion, migration, and apoptosis ${ }^{[15,16,19,23-25]}$. Current evidence suggests that as core CSC proteins, CCM proteins act as scaffolds for many signal molecules and spatiotemporally regulate localization and activity of these proteins, with none possessing innate catalytic activity ${ }^{[26]}$. Homozygous mutations in any of the three CCM proteins are nonviable, indicating their essential role in biogenesis as phenotype suppressors ${ }^{[11-13]}$. We will mainly focus on these three core CSC proteins in this review.

\section{CLINICAL PRESENTATION}

All forms of human CCM mutations induce lesions in the CNS. These lesions are used to follow the course of disease (clinically symptomatic or not) both in the laboratory and in the clinical setting through MRI. A CCM variant observed in the skin tissue is known as hyperkeratotic cutaneous capillary venous malformation $(\mathrm{HCCVM})^{[27]}$. Other cutaneous manifestations include café-au-lait spots, cutaneous venous malformation, and cavernous hemangiomas ${ }^{[2,29]}$. Genetic analysis showed that HCCVMs were only found in patients with a frameshift mutation resulting in a premature stop codon in exon 1 of CCM1. CCM1 mutations have also been associated with hepatic angiomas ${ }^{[30]}$. As for clinical manifestation, CCM1 and CCM2 familial forms are similar while $\mathrm{CCM} 3$ familial form has several unique characteristics. CCM1 and CCM2 mutations result in spinal cavernous angiomas ${ }^{[28]}$. Unlike CCM1 and CCM2 mutations which manifest later, CCM3 mutations manifest as early as age $20^{[31]}$. CCM3 cases have the heaviest disease burden characterized by numerous CNS lesions, with an increased risk of bleeding ${ }^{[32,33]}$. In addition to cutaneous manifestations with premature termination codon mutation in exon 1 of $\mathrm{CCM1}^{[34]}, \mathrm{CCM}_{3}$ mutation cases also present scoliosis ${ }^{[33]}$, mental retardation ${ }^{[35]}$, and meningiomas ${ }^{[31]}$. No other genetic locus for familial forms of CCM has been identified yet ${ }^{[36]}$. However, there are still patients suffering from CCM with normal CCM1, CCM2, and CCM3 genetic screen results. Even utilizing next-generation sequencing to screen the whole genome of CCM patients with known and unknown mutations, no causative mutation among all three CCM loci was detected for these CCM patients ${ }^{[37]}$, further suggesting the existence of a potential new CCM locus.

\section{PROTEIN STRUCTURE}

CCM1 is the largest of the three CCM proteins (736 amino acids) and the most common CCM gene mutated ${ }^{[7,38]}$. $50 \%$ of all familial forms of CCM are due to mutations of $C C M 1^{[36,39]}$. The penetrance of CCM1 mutation 
is around $88 \%{ }^{[40]}$. A recurrent CCM1 missense mutation (Q455X) is prevalent in the Hispanic population, hence it is named common Hispanic mutation ${ }^{[7]}$. It is present in high frequency in southwestern US ${ }^{[41]}$. From N-terminal to C-terminal, CCM1 protein contains a NUDIX domain, three NPxY/F motifs, Ankyrin repeat domain, a FERM domain, nuclear export signal (residues 551-562) ${ }^{[18,25,42]}$ and nuclear localization signals (residues 46-51, 569-572) ${ }^{[23,42-44]}$.

\section{CCM1 C-terminal FERM domain}

Located at the C-terminus (residues 420-736), the FERM domain contains three subdomains (F1-F3). The F1 subdomain of the FERM domain folds into an ubiquitin-like fold, while the F2 subdomain folds into an acylCoA binding fold. Several proteins are known binding partners to this region of $\mathrm{CCM}_{1}^{[45]}$. The F3 subdomain of FERM domain, a bona fide PH domain, binds to NPXY motifs. There have been several reports on this type of interaction in $\mathrm{CCM}_{1}{ }^{[19,46-48]}$. Some reports indicate that the C-terminal FERM domain binds to its first NPXY motif intramolecularly, thereby allowing the CCM1 protein to adopt a closed conformation. They further suggested that in the open conformation, the CCM1 binds to ICAP1 $\alpha$ and localizes it to the cytoplasm and to the nucleus. In the closed conformation, the protein's binding site is inaccessible to ICAP1 $\alpha$ and results in increased CCM1 binding to microtubules through the NUDIX domain, retaining ICAP1 $\alpha$ in the cell membrane. In support of this theory, it was further suggested that cellular binding partners of CCM1 to the F1/ F2 subdomain of the FERM domain or NUDIX domain may drive this conformational change in $\mathrm{CCM1}_{1}^{[47,48]}$. However, new evidence showed that unlike most N-terminal FERM domain-containing proteins, CCM1 (containing a C-terminal FERM domain) does not seem to follow the auto-inhibition mechanism to undergo an intramolecular folding. In fact, both dynamic light scattering (DLS) and native protein gel electrophoresis showed an increased tendency of CCM1 to undergo CCM3 - like oligomerization through intermolecular binding between F3 subdomain of FERM domain and 3 NPXY motifs among partnering CCM1 proteins over intramolecular binding of F3 subdomain of FERM domain - NPXY motifs within CCM1 ${ }^{[19]}$.

\section{CCM1 ankyrin repeat domain}

The ankyrin repeat domain (ARD) domain (residues 288 and 419) in CCM1 is composed of 4 ankyrin repeats. This ARD packs onto the N-terminal side of the F1 subdomain of the FERM domain. Each repeat is identical and composed of two $\alpha$-helices joined by a $\beta$-hairpin. The binding site is between the $\alpha$-helices. These four Ankyrin repeats stack vertically into an "L"-shaped fold. The fourth repeat contains a tripeptide insert (G401, $\mathrm{N} 402$, and N403) in the binding site stabilized by a conversed W404. This tryptophan residue sits in a highly conserved hydrophobic pocket. X-ray crystallography showed that the ARD domain is bound tightly to the FERM domain. This highly conserved interaction is particularly mediated by the convex surfaces of Ankyrin repeats 2 and 3 in ARD domain and the $\beta 2$ strand and $\alpha 2$ helix in F1 subdomain in the FERM domain. This interaction is stabilized by 10-12 hydrogen bonds over 993 A2. The ARD domain was termed as the Fo subdomain in the FERM domain due to its proximity to the FERM domain. The presence of another domain in such as position has been found in other FERM domain - containing proteins, i.e., Talin and Kindlin ${ }^{[49,50]}$. Many proteins such as RAP1 and HEG1 are able to bind to the FERM domain with little to no structural change of the ARD domain required. The ARD in CCM1 is different from other ARD in proteins such as DARPins due to its inability to bind to $\beta$-tubulin. CCM1 was suggested to be a tubulin binding protein, however both structural studies and binding assays show that the ARD domain is not utilized for this interaction ${ }^{[1,52]}$. Till now, there are no known binding partners to the ARD domain in CCM1.

\section{Multiple NPXY motifs in CCM1 protein}

CCM1 also contains 3 NPXY motifs (residues 192-195, NPAY; 231-234, NPLF; 250-253, NPYF) in the central portion of the protein which provide important interactions with phosphotyrosine binding (PTB), $\mathrm{PH}$, FERM domains, etc. The first motif, which is the only one that can be phosphorylated, has a remarkably strong binding affinity to ICAP1 $\alpha^{[20,25]}$. NPXY motifs 2 and 3 can only bind to DAB-like PTB domains, including $\mathrm{CCM} 2^{[18,19]}$. 


\section{CCM1 NUDIX domain}

The NUDIX domain is found in the N-terminus (residues 1-170) of CCM1 and it contains a stretch of basic residues that potentially interacts with microtubules. NUDIX domains are usually found in hydrolases that bind to a variety of substrates. The NUDIX fold in CCM1 is a centrally positioned $\beta$-sheet with flanking $\alpha$-helices. Traditionally, the NUDIX domain contains a NUDIX box which contains the Gx ${ }_{5}$ Ex REUxEExGU motif ${ }^{[53]}$. However, CCM1 doesn't contain a traditional NUDIX motif, yet the tertiary structure of N-terminus of CCM1 still adopts a NUDIX fold. The catalytic residues found in other NUDIX domains are missing in the CCM1 NUDIX domain ${ }^{[54]}$. Therefore, the function of the NUDIX domain in CCM1 may be different from other NUDIX domain-containing proteins. Despite the similarities, superimposition of the X-ray crystal crystallography of the NUDIX domain with known substrates (81 in total) revealed no potential binding partners. Therefore, the function of this domain is still uncertain ${ }^{[54]}$. However, sequence analysis has elucidated the presence of several known sequences such as potential tubulin binding sequence ${ }^{[48]}$ and a nuclear localization sequence (NLS) ${ }^{[42]}$ within the NUDIX domain.

CCM2 is the second largest of the CCM proteins, 444 amino acids in length and contains a PTB domain at the $\mathrm{N}$-terminus and a harmonin homology $(\mathrm{HH})$ domain at the C-terminus ${ }^{[3]}$. $20 \%$ of all familial forms of CCM are due to mutations of $\mathrm{CCM} 2^{[36,39]}$, however, the penetrance of CCM2 mutation was reported to be $100 \%{ }^{[00]}$. CCM2 is found ubiquitously expressed in the endothelial cells (EC) from various organs ${ }^{[55,56]}$. Despite the lack of a recognizable NLS and NES, CCM2 is found in both the nucleus and cytoplasm due to its interaction with $\mathrm{CCM}_{1} 1^{[18,23,57]}$. In the absence of functional CCM1, CCM2 is not localized to the cell junction, however, this function is recovered with the addition of wild-type CCM1, implying that binding to CCM1 is essential for localization of CCM2 to the cell junction ${ }^{[58]}$.

\section{CCM2 HH domain}

CCM2 functions as the scaffold in the CSC with binding sites for both CCM1 and $\mathrm{CCM}^{[16]}$. The HH domain at the C-terminus (residues 283-375) is comprised of 6 packed $\alpha$-helices termed $\mathrm{H}_{1}^{*}, \mathrm{H} 1, \mathrm{H} 2, \mathrm{H} 3, \mathrm{H} 4$, and $\mathrm{H} 5$ in that order from $\mathrm{N}$-terminus to $\mathrm{C}$-terminus. The $\mathrm{H}_{1}{ }^{*}$ is a short $\alpha$-helix with 3 amino acid residues and $\mathrm{H} 4$ is a 3 helix that contains 13 residues. This domain is stabilized by several intramolecular interactions (i.e., R346 to E314, R354 to E366, and P355 to F356). This C-terminal domain bears structural similarity to harmonin protein and therefore termed $\mathrm{HH}$ domain. Although there is structural similarity, $\mathrm{CCM} 2 \mathrm{HH}$ domain is able to bind to neither Cadherin 23 (a validated binding partner of Harmonin) nor to CCM3. This $\mathrm{HH}$ domain exists in two conformations, monomeric and dimeric. The dimeric form has an increased affinity for dimerization; however, there are no sufficient data to affirm the occurrence of dimeric CCM2 in vivo yet ${ }^{[45]}$.

\section{CCM2 PTB domain}

The N-terminus of the CCM2 contains a DAB-like PTB domain ${ }^{[59]}$. This domain contains $2 \beta$-sheets composed of $7 \beta$-strands, with $\alpha$-helices capped at both ends. It was shown that this PTB domain binds to the NPXY motifs present in CCM1. Yeast two-hybrid assays showed that CCM2 PTB domain was able to bind to a CCM1 construct that contained the second and third NPXY motifs but not the first motif ${ }^{[17,18]}$.

CCM3 is the smallest of the $3 \mathrm{CCM}$ proteins with 212 amino acids. CCM3 mutations tend to result in the most aggressive form of the disease $\mathrm{e}^{[8]}$. $10 \%$ of all familial forms of CCM are due to mutations in CCM3 gene ${ }^{[36,39]}$. The penetrance of CCM3 mutation is approximately over $60 \%{ }^{\left[{ }^{[0]}\right]}$. In one study that sought for promoter variants for the CCM genes, two protective single nucleotide polymorphisms were identified in the promoter region of CCM3 (rs9853967 and rs11714980) to be associated with CCMs, while no causative variants were identified in the promoter regions of CCM1 or CCM2, among the selected CCM patient cohort. These variants could partially explain the range of disease burden seen in $\mathrm{CCM}^{[60]}$. $\mathrm{CCM} 3$ is localized to the cis-face of the Golgi body ${ }^{[6]}$. Its interactions with phospholipids, PtdIns ${ }^{[3-5]}$, were believed to facilitate the translocation of $\mathrm{CCM} 3$ to the plasma membran ${ }^{[62]}$. $\mathrm{CCM} 3$ is a 2 -domain-containing protein where both domains are conjoined by a flexible hinge region ${ }^{[63]}$. The tertiary structure of $\mathrm{CCM} 3$ is a V-shaped structure. 
After some invertebrate analogs of $\mathrm{CCM} 3$ were identified and studied, it was found that $\mathrm{CCM} 3$ is the most evolutionarily conserved of the three CCM proteins ${ }^{[64,65]}$. However, CCM1 and CCM2 are predominantly found in the vertebrates ${ }^{[63,66]}$.

\section{ССM3 $\mathrm{N}$-terminal dimerization domain}

CCM3 exists as a homodimer in the cell due to presence of the dimerization domain. It is made up of four $\alpha$-helices: $\alpha_{1}, \alpha_{2}, \alpha_{3}$, and small $\alpha_{4}$. These four $\alpha$-helices interlock with another set of four $\alpha$-helices from a partner $\mathrm{CCM} 3$ dimerization domain. This dimerization domain is also used to bind to GCKIII kinases forming a heterodimer. The interactions between GCKIII and flexible hinge regions of CCM3 control the equilibrium between CCM3 homodimer and CCM3-GCKIII heterodimer ${ }^{[45]}$.

\section{CCM3 C-terminal focal adhesion targeting - homology domain}

The $\mathrm{C}$-terminus of the CCM3 protein contains a focal adhesion targeting-homology domain (FAT-H) domain. This domain is commonly found in some tyrosine kinases such as Pyk2 and FAK. It is also composed of four $\alpha$-helices: $\alpha 5, \alpha 6, \alpha$, and $\alpha 8$. This domain is utilized to bind to large variety proteins including CCM 2 and phosphotidylinositides ${ }^{[62]}$.

\section{NEWLY IDENTIFIED CELLULAR COMPONENTS OF CSC COMPLEX}

CCM1 is highly expressed in EC cells during embryogenesis ${ }^{[67]}$. It is localized ubiquitously throughout the cell including the nucleus ${ }^{[17,20,38,42,68]}$.

\section{CCM1 C-terminal FERM domain}

CCM1 was shown to bind to a small GTPase Rap1 utilizing its FERM domain through X-ray crystallography ${ }^{[43,4]}$ and yeast two-hybrid ${ }^{[69]}$. This interaction localizes CCM1 to the periphery of the cell to facilitate signaling at the cell-cell junctions ${ }^{[48]}$. In contrary, the release of CCM1 from the plasma membrane is due to its interaction with ICAP1 $\alpha$. This complex localizes to the nucleus ${ }^{[17]}$. Rap1 is a GTPase that has many cellular functions such as maintaining cell-cell contacts and integrin-mediated cell adhesion ${ }^{[70]}$. Rap1 is activated by GTPase-activating proteins and CCM1 has a large affinity towards this activated form ${ }^{[71]}$. Disruption of RAP1 and CCM1 interaction results in the absence of CCM1 localization to the cell membrane particularly the adherens junction ${ }^{[71]}$. Superimposition of Rap1 and CCM1 showed that no conformational change was required for bindings to occur ${ }^{[52]}$. The FERM domain contains 3 subdomains F1, F2, and F3. RAP1 binding site in the FERM domain overlaps F1 and F2 subdomains. HRas is another GTPase that binds to the same binding pocket as RAP1. However, in competition assays, RAP1 binds more strongly to CCM1 over HRas due to specific residues in the F2 subdomain of CCM1. This stronger binding affinity to RAP1 is dependent on the interaction of K570 on CCM1 with E45 on RAP1, with respective mutations significantly decreasing binding. Further analysis of the X-ray crystallography of CCM1 and RAP1 showed that the switch II region in RAP1 doesn't contribute to any binding affinity. This is a result of the interaction between Y419 on CCM1 and F64 on RAP1 which destabilizes the switch II region ${ }^{[43]}$. Rap1 acts as an inhibitor of CCM1 interaction with microtubules ${ }^{[4]}$. The inhibition mechanism is the binding of Rap1, releasing CCM1 from the cell membrane and spatially blocking the interaction between CCM1 and microtubules leading to an overall increase in stability of the cell junction ${ }^{[72]}$. Rap1 is found in mice in two forms: Rap1a and Rap1b. Individual deletions of either protein have minimal effect on embryogenesis. However, a combined deletion is embryo lethal. It results in the perineural vessel dilation and hemorrhage, demonstrating the importance of Rap1 in EC cells maturation and angiogenesis. Rap1 deletion was shown to reduce VEGFR2 signaling ${ }^{[73]}$. Unlike CCM1 deletions which result in malformed branchial arches, the formation of patent branchial arches can still be seen in Rap1 deletion, suggesting that CCM1 acts along alternate pathways for vessel formation $^{[74]}$. CCM1 FERM domain also binds to HEG1 protein, which further enables CCM1 localization at the cell junction. HEG1 is a transmembrane protein that contains an NPxY motif on its cytoplasmic tail. The binding pocket of HEG1 in CCM1 does not overlap with RAP1. The binding strength of HEG1 to 
CCM1 is independent of binding to RAP1. HEG1 interacts with the hydrophobic pocket between F1 and F3 subdomain. The interaction between HEG1 and CCM1 is trifold: F1 subdomain through polar interactions, $\mathrm{F} 3$ subdomain through hydrophobic interaction, and $\alpha_{2} \mathrm{~A}$ helix between $\mathrm{F} 1$ and $\mathrm{F} 3$ subdomain. Analysis of electron density shows that the C-terminal dipeptide on HEG1 of tyrosine-phenylalanine is critical for their binding. This binding is not in the category of the classical PH (F3 subdomain) - NPxY motif interaction. In fact, the binding pocket is similar to the inositol phosphate binding site in the $\mathrm{PH}$ domain ${ }^{[75]}$. Similar to the binding of RAP1, the binding of HEG1 doesn't illicit any conformational change in the FERM domain ${ }^{[43]}$. The binding of CCM1 with HEG1 and RAP1 is essential for appropriate cardiovascular development, and disruption of these interactions was shown to cause the phenotype of $\mathrm{CCM}^{[71]}$. Heg1-null zebrafishes manifest with the same cardiovascular phenotype as $\mathrm{Ccm} 1$ null mutants ${ }^{[76]}$. Infusion of CCM1 mutants lacking the binding ability to RAP1 and HEG1 into $\mathrm{Ccm} 1$ null zebrafish could not reverse the cardiovascular phenotype ${ }^{[71,76]}$, indicating the essential role of the interaction.

\section{Multiple NPXY motifs in CCM1 protein}

CCM1 binds to ICAP1 $\alpha$ and acts a competitive inhibitor of ICAP1 $\alpha$ and $\beta 1$-integrin interactions[20,68]. ICAP $1 \alpha$ contains a PTB domain that binds to $\beta 1$-integrin and modulate $\beta 1$-integrin mediated cellular function $^{[15,23-25,54]}$. Mutagenesis of the T778 and V790 or N792 and Y795 of the cytoplasmic tails of $\beta 1$-integrin prevents binding to ICAP $1 \alpha$. However, the exact consequence of this interaction is not fully agreed upon. The overwhelming theory is that CCM 1 acts to sequester ICAP1 $\alpha$ resulting in increased levels of $\beta 1$-integrin activation because ICAP $1 \alpha$ is a potent repressor of $\beta 1$-integrins ${ }^{[15,23-25,54]}$. However, one study suggests that CCM1 interaction with ICAP1 $\alpha$ stabilizes ICAP1 $\alpha$, therefore increasing $\beta 1$-integrin activation. This effect is profound when low levels of CCM1 results in paradoxically increased $\beta 1$-integrin activation.However, appropriate amount of $\beta 1$-integrin is necessary for development of vascular sinusoids ${ }^{[77]}$, cell cycle ${ }^{[78,79]}$, and bone development ${ }^{[80,81]}$. ICAP1 $\alpha$ PTB domain is a DAB-like PTB domain where the interaction between ICAP1 $\alpha$ and CCM1 is independent of the phosphorylation status of the NPXY motif. Binding of CCM1 or $\beta 1$-integrin to ICAP1 $\alpha$ doesn't result in any structural changes ${ }^{[82]}$. CCM1 binding to ICAP1 $\alpha$ through a bidentate interaction with the ICAP $1 \alpha$ PTB domain. This interaction is identical to ICAP1 $\alpha$ and $\beta 1$-integrin interaction thereby resulting in competitive inhibition ${ }^{[1,23-25]}$. CCM1 utilizes the first NPXY motif and a RR region to bind to ICAP $1 \alpha$ PTB domain ${ }^{[83]}$. The RR region is a novel site that binds to the N-terminus of NPXY motif. This $\mathrm{N}$ - terminal region adopts an $\alpha$-helix confirmation that binds to the loop between $\beta 1$ and $\beta 2$ and well as $\beta 5$ and $\beta 6$ and $\alpha 1$ helix of the PTB domain ${ }^{[82]}$. The interaction between the PTB domain and the RR site is mediated by the conserved arginine residues on the CCM1 (R179 and R185), binding to polar side chains such as the carbonyl groups of D146, D93, and Q96 on ICAP1 $\alpha$. The interaction of the PTB domain and the NPxY motif is mediated by the interaction of N192 and Y195 on CCM1 to the ICAP1 $\alpha$ binding site of PTB domain, L135, I138, I139, and C184. Mutation in the NPXY binding sites on ICAP1 $\alpha$ inhibits binding to cytoplasmic tail of $\beta 1$ integrin. However, mutation in the RR binding sites (D146, D93, and Q96) did not affect binding with cytoplasmic tail of $\beta_{1}$ integrin. Therefore, unlike CCM1-ICAP1 $\alpha$ interaction, the binding between ICAP1 $\alpha$ and $\beta 1$-integrin is not a bidentate interaction ${ }^{[54]}$.

CCM1 binds to CCM2 and SNX17 through the utilization of the second and third NPXY motifs ${ }^{[18,19,59,84]}$. Biochemical studies demonstrate that CCM2 utilizes its PTB domain to bind to the third NPXY motif of CCM1. Several leucine residues in CCM2 (L113, L115, L155, L198, and L213) are paramount for adequate binding to CCM1. Several residues downstreaming to the NPXY motif such as V244 and V248 are also important. Even a conservative mutation like V244L was found to significantly decrease binding. An X-ray crystallography of CCM2 with the third NPxY motif of CCM1 was determined. However, Co-IP shows that both the second and third NPxY motifs are required to bind to $\mathrm{CCM}^{[18]}$. Additionally, biochemical studies do not show an increased affinity with a construct containing both the second and third NPxY motifs over just the third NPxY motif ${ }^{[59]}$. 


\section{CCM2 PTB domain}

Some PTB domains can bind to phospholipids and it was expected that such an affinity in CCM2 PTB domain will transport CCM2 complex to the plasma membrane, however no consensus has been reached in that regard. One study stated that CCM2 PTB domain is able to bind to phospholipids ${ }^{[85]}$, while other studies suggested the opposite $^{[3,19]}$. CCM2 PTB domain has been shown to interact with two proteins, TrkA and Smurf1. TrkA is present in neurons. The PTB domain of CCM2 binds to the cytoplasmic tail of TrkA ${ }^{[86]}$. This complex binds with $\mathrm{CCM} 3$ and STK25 to form a large complex. This may happen through a direct mechanism where CCM2 brings $\mathrm{CCM} 3$ or an indirect mechanism. However, the formation of this complex leads to apoptosis. This pathway is found to be especially important in the field of prognostic and therapeutic aspects of neuroblastoma and medulloblastoma ${ }^{[87]}$. CCM2 PTB domain was also reported to bind to Smurf1 HECT domain. This interaction brings Smurf1 to the plasma membrane ${ }^{[88]}$. This interaction has been related to RhoA degradation.The lack of RhoA degradation results in uncurbed activation of Rho-associated coiled coil-forming kinase (ROCK) which leads to stress fiber formation ${ }^{[89]}$. One report stated that CCM2 protein in macrophages is found adjacent to newly synthesized actin polymers. This localization of CCM2 is compatible with the predicted function of regulating RhoA because RhoA is active in actively synthesizing actin polymers ${ }^{[22]}$.

\section{CCM2 C-terminal HH domain}

A four nucleotide duplication of the last exon of CCM2 was introduced to create a mutation disrupting the structure of the $\mathrm{HH}$ domain at the C-terminus. This mutated form of CCM2 protein was able to bind to $\mathrm{CCM} 1$ and $\mathrm{CCM} 3$, however unable to bind to MEKK3, a Map3 kinase, suggesting that the $\mathrm{HH}$ domain mediates the interaction between $\mathrm{CCM} 2$ and $\mathrm{MEKK} 3^{[90]}$.

\section{CCM2 KARET domain and LD motif}

Some reports showed that CCM2 interacted with CCM3 through a KARET domain at the C-terminus of CCM2 (residues 228-444), which overlaps with $\mathrm{HH}$ domain ${ }^{[16,17,63,86,87]}$. However, it was recently shown through pull-down assays that the binding pocket was located in the middle of CCM2 (residues 223-238), between the N-terminal PTB domain and C-terminal HH domain. This region was determined to contain a LD motif, which binds to FAT-H domain on CCM3. The FAT-H domain of CCM3 contains a hydrophobic pocket termed HP1 which is the binding site for CCM2. The LD motif adopts a 3.5 turn $\alpha$-helix parallel to $\alpha 7$-helix in CCM3. The interaction is largely made up of hydrophobic residues from CCM2 (T225, I226, F228, L229, A232, I233, G236, and A237) binding to hydrophobic residues from CCM3 (I131, I134, A135, I138, L142, V168, F174, L178, S171, K132, and K139). These hydrophobic resides are also extremely conserved through evolution, indicating their significance ${ }^{[63]}$. CCM2-CCM3 complex formation reciprocally protects the proteins from degradation. Either CCM2 or CCM3 depletions result in concurrent decreases in the reciprocal protein. Furthermore, CCM2 and $\mathrm{CCM} 3$ mutated cells grew slower than wild-type ones. This mutant phenotype can be rescued with the addition of CCM2 or CCM3. Overexpression of CCM2 in CCM3depleted cells did not restore cellular proliferation, however overexpression of CCM3 in CCM2-depleted cells did, indicating that the CCM3 may have a greater contribution to cell proliferation ${ }^{[91]}$.

\section{CCM2-Like protein}

Recently CCM2-Like (Ccm2l) protein was identified in zebrafish. This protein bears large sequence similarity to CCM2. It contains a PH domain as opposed to a PTB domain, found in CCM2. Our lab showed that PTB domains and PH domains can have overlapping abilities ${ }^{[19]}$. Despite the similarities, the function of Ccm2l and CCM2 are not identical. The N-terminus of CCM1, which contains the NPxY motifs, can bind to Ccm2l, potentially through the $\mathrm{PH}$ domain. Although, it is still unknown which of the three NPxY motifs are used by $\mathrm{Ccm} 2 \mathrm{l}$ for binding. $\mathrm{Ccm} 21$, which is selectively expressed in $\mathrm{EC}^{[92]}$, sequesters CCM1 by acting as a competitive inhibitor, however, it is unable to bind to CCM3. The ability to bind to CCM1 results in the inhibition of CCM2 mediated junctional stability. During embryogenesis, Ccm1 is expressed in the notochord while Ccm2 is expressed heavily in tissue anterior to the notochord. Interestingly, Ccm 21 is found in both regions. Despite these differences, $\mathrm{Ccm} 2 \mathrm{l}$ knockout zebrafish exhibits cardiac phenotype, i.e., 
cardiomegaly. This phenotype is seen to a milder extent in $\mathrm{Ccm} 1, \mathrm{Ccm} 2$, and Heg1 null mutants. The effect of $\mathrm{Ccm} 2 \mathrm{l}$ is more pronounced in the heart than large vessels. In fact, there is partial phenotypic rescue with $\mathrm{Ccm} 2$ over-induction in Ccm2l-null zebrafish. Therefore, it is concluded that Ccm2l acts in the Heg-Ccm pathway ${ }^{[93]}$. It is still unclear whether CCM2L is involved in the pathogenesis of $\mathrm{CCM}^{[26]}$.

\section{CCM3 dimerization}

The N-terminus of one $\mathrm{CCM} 3$ can bind to another $\mathrm{CCM} 3$ in the native state, driven by identical hydrophobic

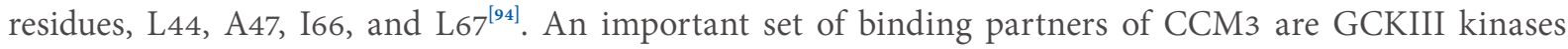
such as Mst4 and Stk25. These kinases contain an N-terminal catalytic domain and C-terminal regulatory domain. The C-terminal regulatory domain of GCKIII can bind to dimerization domain in CCM3. The tertiary structure of the C-terminus of GCKIII is similar to the N-terminus of CCM3 and can compete with and replace a $\mathrm{CCM}_{3}$ in the $\mathrm{CCM} 3$ homodimer. These kinases adopt an independent V-shaped domain as well. Each side of the V in the GCKIII protein is made up of several $\alpha$-helices. Mutations in the hydrophobic residues that removed CCM3 dimerization effectively also inhibit GCKIII and CCM3 binding ${ }^{[95]}$. However, CCM3 has higher binding affinity to GCKIII kinases over CCM3 homodimer. There exists a long linker peptide in CCM3 between $\alpha_{3}$ and $\alpha 4$ helix along the CCM3 protein. In the homodimer state, this region folds into $\alpha$-helix and merges with $\alpha 4$ forming an extended helix. This extended helix is stabilized by hydrophobic residues found in the antiparallel $\alpha 1$ helix in the partner CCM3 within the homodimer. Hydrophobic residues (V72, F76, L80, M83) in the extended $\alpha 4$ helix interact with hydrophobic residues (V25, A24, P21, M20, V18, and M17) in $\alpha 1$ helix of partner CCM3. This stabilizing interaction doesn't occur in the GCKIII-CCM3 complex, because the corresponding $\alpha_{1}$ helix in GCKIII doesn't contain any hydrophobic residues. In the interaction between CCM3-GCKIII, the linker region between $\alpha_{3}$ and $\alpha 4$ helices in CCM3 is less structured and able to adopt a flexible conformation. This allows hydrophobic residues (F76, L80, and M83) in $\alpha 4$ helix in CCM3 to fall into a hydrophobic pocket formed by $\alpha_{1}$ and $\alpha_{3}$ helix in CCM3 through intra-molecular binding. This twisting of the CCM3 causes in the full N-terminal face of CCM3 to interact with the full C-terminal face of GCKIII, which doesn't occur in the homodimer of CCM3 due to the inherent bend in the CCM3 tertiary structure ${ }^{[63,96]}$. Therefore, there is a larger binding area between CCM3 and GCKIII. This larger-interface interaction present results in a much higher binding affinity ${ }^{[95]}$.

Knockout models of Stk24 and Stk25 caused cardiovascular disease similar to that observed in CCM3 knockout models ${ }^{[97]}$. STK25, a serine/threonine kinase, controls RhoA activation, which is a GTPase. Loss of RhoA results in stress fiber formation ${ }^{[98]}$. It has been well documented that CCM phenotype causes increased stress fiber formation; however several reports contradicted this finding ${ }^{[99,100]}$. Increase RhoA activation leads to increased ROCK. ROCK is another serine/threonine kinase that phosphorylates several proteins: myosin light chain, MLC phosphatase, and LIM kinase. MLC phosphatase decreases the cross linking of myosin and actin, the source of fiber contractility. Phosphorylation by ROCK inhibits MLC phosphatase. In contrast, ROCK dependent phosphorylation of LIM kinase results in activation. Active LIM kinase catalyzes phosphorylation of cofilin, which inhibits cofilin activity that regulates actin depolymerization. Both pathways, LIM kinase and MLC phosphatase, lead to stress fiber formation. ROCK inhibition results in regression of stress fiber ${ }^{[26]}$. Increases in ROCK activity have been recorded in CCM lesions. Interestingly, increases in ROCK activity have been seen in histologically normal blood vessels in CCM1 deficient mice, suggesting possible involvement of ROCK signaling in the pathogenesis of CCM lesions ${ }^{[101]}$.

\section{CCM3 C-terminal FAT-H domain}

$\mathrm{CCM} 3$ contains a FAT-H domain at the $\mathrm{C}$ - terminus that is used to bind to CCM2. The surface of the domain contains a hydrophobic patch termed hydrophobic patch 1 (HP1), which is found between $\alpha 7$ and $\alpha 8$ helix. This is the site for binding various proteins such as $\mathrm{CCM}_{2} 2^{[63]}$, striatins ${ }^{[6]]}$, and paxillin ${ }^{[102]}$. For interaction of both stratins and paxillin, CCM3 recognizes LD motifs that adopt helical structures. Compared to CCM2CCM3 complex, CCM3-paxillin complex has a smaller surface area, the LD motif is smaller ( 2 turns), and the LD motif helix is less parallel to $\alpha 7$ helix in $\mathrm{CCM}_{3}{ }^{[91]}$. Paxillin is known to bind to FAT-H domains 
in FAK and Pyk2 ${ }^{[63]}$. Through fluorescence images, it was determined that paxillin and CCM3 were colocalized to the plasma membrane at the leading edge ${ }^{[102]}$. The functionality of this binding is still unknown, one hypothesis is that the formation of some CCM3-GCKIII complexes is under the control of paxillin phosphorylation. Therefore, paxillin may be sequestering CCM3 from activity ${ }^{[103]}$.

\section{CELLULAR SIGNAL TRANSDUCTION \\ CCM1 plays a role in Notch signaling}

Cells with increased CCM1 activity show overexpression of HEY1 and DLL4, two major players in notch signaling. Notch signaling increases PI3K/AKT signal pathway and activated AKT leads to suppression of ERK1/2 by dephosphorylation. CCM1 deficient cells and CCM lesions show increased phosphorylation of ERK $1 / 2^{[104]}$. AKT phosphorylation is also important in regulating the expression of SOD2, which is an important free radical scavenger in the cell. SOD2 is upregulated with increases in reactive oxygen species through AKT phosphorylation. In the absence of CCM1, AKT phosphorylation is decreased ${ }^{[72,105]}$, leading to decreased expression of SOD2, and therefore increasing oxidative damage in the cell ${ }^{[106]}$. CCM1 is also an inducer of SOD2 through interaction of ND1. ND1 is an important actin stabilization protein that binds to CCM1. This interaction increases the expression of SOD2. Therefore, CCM1 can prevent oxidative damage and cell death through complex induction of $\mathrm{SOD} 2^{[107]}$.

\section{CCM1 involved in KLF4/KLF2 signaling pathways}

Both in vivo studies with Ccm1 knockout mice and in vitro studies with CCM1 silencing in human brain EC (hCMEC) showed elevation of KLF4 nuclear signal. KLF4 has been reported to play an important role in EC in biogenesis of veins and angiogenesis in general. Combined silencing of both KLF4 and CCM1 significantly decreases the disease mortality (75\% reduction of mouse mortality) and modest improvement of vascular lesions (reduced vascular density in retina). The prototypical lesions in CCM lack mesenchymal intervening tissue, which is due to increased proliferation and dysfunctional migration, both of which are mediated with KLF4 inhibition. In this signaling pathway, CCM1 binds and sequesters MEKK3, which in turn activates MEK5, which subsequently activates ERK $5^{[108,109]}$. ERK5 is a known inducer of KLF4 in EC cells $^{[110-112]}$. KLF4 is a transcription factor which activates BMP6 and decreases SMAD1 phosphorylation. It has been shown that SMAD is activated in CCM deficient condition and leads to active BMP6 and TGF- $\beta$. These two downstream proteins mitigate the histological manifestation of CCM, i.e., lack of intervening parenchyma ${ }^{[113]}$. KLF2 is another transcription factor that is induced by a similar signaling cascade ${ }^{[114]}$. KLF2 is responsible for the cardiac manifestations and increased angiogenesis seen in $\mathrm{CCM}^{[115,116]}$. KLF4/KLF2 are transcription factors that suppress expression of thrombospondin1 (TSP1) which functions as an angiogenic inhibitor $^{[117]}$. Loss of TSP1 was found to exacerbate CCM phenotype in $\mathrm{Ccm} 1$ deficient mice. Abnormalities of cell-cell junction are found to be the initial manifestation of CCM1. It was found that decreases in Claudin-5 and ZO-1 levels were the first to be observed before changes in VE-cadherin levels. The perturbed expression of these cell junction proteins can be rescued in $C c m 1$ knockout mice with exogenous TSP1 (3TSR). 3TSR was found to decrease both VEGR2 phosphorylation leading to decreased angiogenesis and increased TGF- $\beta$ activation. Furthermore, this treatment decreases the lesion burden in mice. Therefore, there is a possibility to utilize KLF4 inhibitors, ERK5 inhibitors, or exogenous TSP1 for potential therapeutic applications in CCM in the near future ${ }^{[118]}$.

\section{CCM1 is a key player in integrin signaling}

$\beta 1$-integrin signaling is an important regulator in many cellular functions such as cellular migration and adhesion $^{[15,24,25,57]}$. These functions are especially important for EC cells. ICAP1 $\alpha$ is a repressor of $\beta 1$-integrin signaling ${ }^{[46]}$. Our previous results indicate that CCM1 binds to ICAP1 $\alpha$ and modulates ICAP1 $\alpha$ and $\beta 1$-integrin interaction. Depletion of CCM1 and ICAP1 $\alpha$ synergistically inhibits extracellular signal-regulated kinase/ mitogen-activated protein (ERK/MAP) kinase pathway activation on cell survival ${ }^{[15,23-25,57,72]}$. We hypothesized that CCM1 regulated recruitment of ICAP1 $\alpha$ to the cell membrane in proximity to focal adhesions, which 
may be critical for the maintenance of cellular architecture as well as regulation of $\beta 1$-integrin-mediated signaling $^{[25]}$. The follow-up studies found that ICAP1 $\alpha$ deficiencies result in many osteoblastic defects which are the direct results of $\beta 1$-integrin activation. CCM1 acts as a competitive inhibitor for the interaction of ICAP $1 \alpha$ and $\beta 1$ integrin. The lack of inhibition of ICAP $1 \alpha$ leads to excessive inhibition of $\beta 1$-integrin which is thought to cause the leaky vasculature found in $\mathrm{CCM}^{[54]}$. $\mathrm{CCM} 1$ has been reported to be responsible for localization of ICAP1 $\alpha$ to the nucleus, through the use of the N-terminus $\mathrm{NLS}^{[42]}$. It was shown that only in the presence on intact CCM1- ICAP1 $\alpha$ interaction and functional NLS in CCM1 does ICAP1 $\alpha$ localize to the nucleus ${ }^{[47]}$. However, ICAP1 $\alpha$ also contains a NLS and drives CCM1 localization to the nucleus. In the absence of ICAP1 $\alpha$, CCM 1 is evenly spread throughout the cell, but in the presence ICAP1 $\alpha$, the CCM1 localizes to the nucleus. Alanine walking in NLS1, NLS2, and NES in CCM1 showed that only NLS1 affected CCM1 localization. NLS2 and NES mutation showed identical CCM1 localization to wild-type CCM1. However, functional ICAP1 $\alpha$ is able to translocate NLS1 mutated CCM1 into the nucleus. However, the N-terminus of CCM1 is unable to translocate ICAP1 $\alpha$ with a deficient NLS. The addition of CCM1 to ICAP1 $\alpha$-silenced cells results in CCM1 accumulation only in the cytoplasm, suggesting that ICAP1 $\alpha$ drives localization of CCM1, not the other way around ${ }^{[119]}$.

\section{CCM proteins modulate VEGF signaling}

Mutations in CCM1 and $\mathrm{CCM} 3$ were found to increase translocation of $\beta$-catenin from the cytosol to the nucleus. This leads to increased expression of various proteins such as VEGF-A, which can be further reversed by the addition of a $\beta$ catenin transcription inhibitor. The increased level of VEGR-A activates VEGFR2, which is shown by increased VEGFR2 phosphorylation. This increases the endothelial cell (EC) permeability, leading to vascular leakage. This phenotype can be rescued with the addition of VEGFR2 inhibitors in both in vitro and in vivo conditions. Interestingly, VEGF inhibition blocked the formation of stress fiber formation. Therefore, the stress fiber formation is caused to some extent by VEGF signaling. Furthermore, enhanced VEGF signaling results in increased cellular migration. A wound-healing assay showed that CCM1 deficient cells had a $25 \%$ increase in migration compared to the cultured cells treated with VEGF. However, this phenotype can be reversed in the CCM1-null cells with the treatment of VEGF inhibitors. VEGFR2 phosphorylation results in downstream phosphorylation of $\beta$-catenin and VE-cadherin, which results in disruption of interaction with $\alpha$-catenin ${ }^{[120]}$ and p120 catenin ${ }^{[121]}$ respectively. This results in translocation of $\beta$-catenin into the nucleus for further downstream effects. However, VEGF inhibitors were not sufficient to inhibit the $\beta$-catenin and VE-cadherin disassociation seen in CCM1 deficiency, suggesting that other mechanisms are involved for the disassociation ${ }^{[122]}$.

\section{CCM2 modulates MAPK signaling}

CCM2 leads to downstream activation of p38 MAPK, which is upregulated in osmotic shock. It is still unclear for the role of the CCM2 in the p38 MAPK activation pathway. One report stated that CCM2 localizes to the cell membrane where it facilitates binding MEKK3 and RAC1 leading to activation of MAPK ${ }^{[17,22]}$. Another report showed that $\mathrm{CCM} 2$ is able to bind to F-actin, suggesting that $\mathrm{CCM} 2$ forms a complex that links RAC1-dependent actin reorganization to 338 MAPK signal pathway ${ }^{[123]}$. Another report showed that the signaling pathway is through phospholipase C (PLC). The complex of CCM2-RAC1 causes a change in PLC cascade, leading to MAPK activation ${ }^{[124]}$. While another report showed that CCM2 affects the JNK and MKK signaling leading to an alternative pathway to promote MAPK activation ${ }^{[89]}$.

\section{CCM3 plays a role in Notch signaling}

In recent years, several mechanisms for the pathogenesis of CCMs have been proposed such as decreased Notch signaling ${ }^{[125]}$, increased VEGF signaling ${ }^{[126]}$, or increased ERK activity in the deficiency of $\mathrm{CCM}^{[127]}$. It has been recently reported that CCM3 affects EC function by regulation of DLL4 $4^{[128]}$. Down-regulation of CCM3 resulted in decreased expression of DLL4 and Notch4, but no change was observed in Notch1. This was shown in both cell lines and brain tissue in CCM patients. In fact, the vascular phenotype found in CCM3 mutants can be replicated through mutations in DLL4. Aberrant DLL4/notch signaling results in 
overexpression of vasodilators during angiogenesis. The phenotype of hyperangiogenesis in CCM3 deficient condition can be rescued by overexpression of DLL4. Abnormal Notch signaling leads to many downstream effects. Notch signaling is also reported to be involved in the regulation of expression of VEGF receptors, to modulate vascular bed architecture ${ }^{[129]}$ and angiogenesis ${ }^{[39,130]}$. In fact, CCM3 deficient cells increase the expression levels of VEGF which affects cell survival through ERK1/2 activity ${ }^{[131]}$. ERK1/2 kinase was reported to be upregulated in CCM3 deficient lesions, which can be reversed when DLL4 function is rescued through induction of recombinant DLL4. Therefore, CCM3-mediated notch signaling also affects ERK1/2 and VEGF functions leading to abnormalities in EC cells. The finding that CCM3 deficient phenotype can be rescued through DLL4 overexpression creates a promising venue for future pharmacotherapy ${ }^{[126]}$.

\section{TLR4 signaling in CCM pathogenesis}

It was found that induction of gram negative bacterial abscesses in $\mathrm{Ccm} 1$ and $\mathrm{Ccm} 2$ deficient mice significantly increased the phenotypic severity of CCM lesions. The effect was increased in mice with hematogenous infections of gram-negative bacteria. In fact, exposure to just lipopolysaccharide (LPS) was sufficient for significant lesion formation in the mice. It is well known that LPS response is mediated by TLR4 pathway ${ }^{[32]}$ and that MEKK3 deficiency terminates the signal ${ }^{[133]}$. MEKK3-KLF2/4 pathway has already been implicated in CCM lesion formation ${ }^{[90]}$, which is further validated by decreased expression of KLF2/KLF4 with an LPS injection, suggesting the existence of TLR4-MEKK3-KLF2/4 pathway. Furthermore, heterozygous TLR4 mutants had a significantly decreased CCM lesion formation and homozygous mutants had a complete resolution of CCM lesions. This suggests that TLR4 signaling drives CCM lesions development. In fact, genetic polymorphisms in TLR4 (rs10759930) and CD14 (rs778587) (a TLR4 co-receptor) that result in increased expression of respective proteins do result in increased CCM lesions. These findings were further supported by lack of CCM lesion formation in mice that were surgically removed as fetuses and grown in sterile conditions. Therefore, exogenous stimulation of TLR4 may be involved in CCM lesion formation. Two additional experiments were also performed to prove post-natal suppression of lesion can be achieved: (1) TLR4 antagonists can decrease lesion severity in mice through decreased TLR4 signaling; (2) the course of antibiotics also decreases lesion severity. These antibiotics altered the nature of the microbiome in the mice for decreased TLR4 stimulation. This report provides a new avenue for potential CCM pharmacotherapy ${ }^{[134]}$.

\section{CELLULAR FUNCTIONS AND BIOGENESIS}

\section{Angiogenesis}

CCM lesions are hallmarked by abnormally increased EC proliferation. There are many proposed mechanisms for angiogenesis implicated in CCM. ICAP1 $\alpha$ is involved in NOTCH signaling. Therefore, loss of CCM1 or ICAP1 $\alpha$ results in increased angiogenesis ${ }^{[104]}$. $\mathrm{CCM}_{3}$ is also reported to be involved in NOTCH signaling resulting in increased angiogenesis ${ }^{[126]}$. CCM proteins also modulate MAP kinase activity which in turn modulates angiogenesis ${ }^{[89]}$. It is also reported that CCM3 increases VEGF receptor concentrations, thereby resulting in increased EC proliferation ${ }^{[135]}$. However, there is still controversy of the mechanistic pathways for control of angiogenesis by the CCM proteins ${ }^{[2,136]}$.

\section{Microvascular integrity}

CCM lesions are not only hallmarked by the presence of abnormal EC proliferation and migration but also increase the leakage predisposing the lesions to hemorrhage. There are several explanations for this phenomenon. ANKS1B is a novel PTB domain containing protein that binds to the third NPXY motif in CCM1. No change of EC cell proliferation, migration or sprouting was observed in ANKS1B-deficient EC, suggesting that $A N K S 1 B$-deficiency did not affect the CCM1 activity or Notch signaling. However, these EC cells had decreased transendothelial resistance (TER), which cannot be rescued by ROCK inhibitors. This observation indicates that ANKS1B regulated EC cell adhesion without involving RhoA signaling. Further, increased TER was achieved by overexpression of ANKS1B in CCM1 depletion, indicating that CCM1 is not involved in ANKS1B signaling either ${ }^{[137]}$. Another explanation is that the increased vascular permeability 
is due to stress fiber formation in CCM lesions. CCM proteins are responsible for inhibiting Rho kinase. However, unopposed activation of Rho kinase results in increased phosphorylation of myosin light chain, which was also seen in CCM lesions ${ }^{[58]}$. Another theory is the dysfunction of RAP1 and CCM1. CCM1 acts as a scaffold for RAP1 and is important for cell junction protein $\beta$-catenin and VE-Cadherin, thereby stabilizing the cell membrane. VE-Cadherin is a part of the adherens junction ${ }^{[138]}$. Therefore, dysfunction of VE-Cadherin affects cell contacts. $\beta$-catenin is a nuclear factor. Dysfunction of CCM proteins results in increased translocation of $\beta$-catenin in the nucleus that lead to EC proliferation ${ }^{[139]}$.

The vascular permeability seen in $\mathrm{Ccm} 1$ knockout mice can be rescued by SOD2 and catalase infusions with antibody-mediated targeting to the endothelium. TNF- $\alpha$ was able to induce vascular permeability in the arterioles in these rescued mice. However, TNF- $\alpha$ is unable to induce vascular permeability in Ccm 1 null mice. It was also shown that in the absence of CCM1, TNF- $\alpha$ was unable to generate ROS. This suggests that TNF- $\alpha$ function involves CCM1. Yet, CCM lesions have shown to have elevated ROS. This is a result of increased activity of NADPH oxidases (NOX). Both in vitro and in vivo CCM lesions showed significant up-regulation of NOX4. NOX4 is not only a source of ROS, but also an enhancer for downstream activation

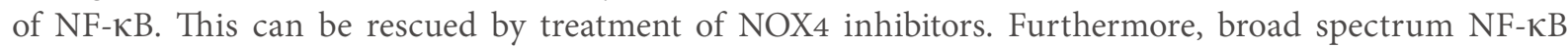
inhibitor (i.e., N-(E)-p-coumaroyl-3-hydroxyanthranilic acid, YAv1) inhibits NF- $\kappa$ B activation due to NOX4 or TNF- $\alpha$, which can rescue the defective endothelial barrier seen in $\mathrm{CCM}^{[140]}$. These inhibitors could potentially be utilized for CCM pharmacotherapy in the future.

\section{CCM1 protects cells from oxidative damage}

All three CCM proteins follow a knudsonian pattern of inheritance. Therefore, a second mutation is necessary for development of lesions and reactive oxidative species are a source of DNA mutations. Initially, $\mathrm{Ccm}$ mouse models were made with $\mathrm{Ccm} 1$ and $\mathrm{Ccm} 2$ heterozygous mutant mice. However, these mice never showed any CCM lesion phenotype, so another mutation, Msh2, was developed into these mice. Msh2 is a DNA damage-repair protein that decreases DNA mutations. Only mice with heterozygous Ccm1 and homozygous Msh2 deletion showed considerable vascular CCM lesions ${ }^{[101]}$. Ccm1 is a regulator of FoxO1, through an unknown mechanism. This transcription factor induces the transcription of Sod2 and Sirt1, two important anti-oxidants in the cell ${ }^{[106]}$. It was also shown that CCM1 can regulate Rho GTPase, by interacting with ND1-L in the presence of oxidative stress ${ }^{[107]}$. Another potential pathway modulated by CCM1 to limit oxidative stress is JNK/c-Jun signaling. In CCM1-null cells, there is an overexpression of C-Jun which can be reversed by reintroduction of CCM1. Therefore, CCM1 protects the cells from downstream oxidative stress of C-Jun redox pathways ${ }^{[141]}$. The cells lacking CCM1 also have increased activity of COX-2, a mediator of inflammatory pathways in the cells ${ }^{[142]}$. This is consistent with the in vivo data that $C \mathrm{~cm} 1$ knockout mice had hyper-exaggerated response to inflammatory agents ${ }^{[143]}$. Therefore, it can be concluded that inflammation and oxidative stress are involved in CCM lesion formation ${ }^{[144]}$. CCM1 provides protection against oxidative stress in the cell by utilizing anti-inflammatory and anti-oxidant pathways ${ }^{[106]}$.

CCM is associated with increased ROS that mediate cellular damage. The cell usually responds through up-regulation of anti-oxidant enzymes. CCM1 depletion induced lesions show increased levels of Nrf2 transcription factor and Glo1 enzyme, both having important anti-oxidant functions in the cell. This results in a paradoxical increase in cell death due to protective mechanisms. However, chronically activated antioxidant mechanisms result in impairment of regular redox reactions in the cell. Many other vascular diseases have overactivation of $\mathrm{Nrf}_{2}{ }^{[145,146]}$. It was shown that chronic $\mathrm{Nrf} 2$ activation as seen in CCM is paradoxically associated with increased ROS production. This, in accordance with other studies, shows that the antioxidative effects of Nrf2 are only seen at certain concentration levels ${ }^{[147]}$. Loss of function (LOF) of CCM1 results in increased JNK signaling, which has been shown to lead to increased Nrf2 activity ${ }^{[148,149]}$. JNK inhibitors resulted in decreased Nrf2 activation and restored ability of autophagy. Impaired autophagy is seen in CCM lesions and rescue of this phenotype suggest that it is mediated by JNK signal pathway. Similar 
to Nrf2, supraphysiological concentrations of Glo1 result in increased sensitivity to oxidative stressors ${ }^{[150,151]}$. These cells also have decreased levels of heat shock protein (HSP), Hsp70 and Hsp27, which have a protective role in the cell by increasing cellular capacity to handle stressors. The sequential effects by Glo1 compound to increase sensitivity to stressors and decrease tolerance, result in greater propensity towards intrinsic cell death in CCM1 deficient condition ${ }^{[152]}$.

\section{Appropriate valvulogenesis is predicated on CCM1-CCM2 complex}

The fluid stress on the EC cells is paramount for appropriate differentiation of the heart. It is shown that abnormalities in blood flow through alteration of KLF2a/b activity affect heg1. Heg1 is localized to areas of myocardium with increase fluid forces in zebrafish ${ }^{[153]}$. It was found the increased Heg 1 expression stabilized $\mathrm{Ccm} 1$ in these cells. Therefore, overexpression of Heg1 resulted in increased $\mathrm{Ccm} 1$ leading to decreased Klf2a activity. This decreased Klf2a activity desensitizes the cells to the fluid forces resulting in appropriate valvulogenesis. In the absence of $\mathrm{Ccm} 1$, the endocardial cushions do not develop into functional valves. Induced expression of $\mathrm{Ccm} 1$ to endocardial cushions in $\mathrm{Ccm} 1$ deficient zebrafish resulted in development of valves. These cells were shown to increase Notch signaling and decrease Klf2a activity with the targeted expression of $\mathrm{Ccm} 1$. Similar valvular defects were also seen with the inhibition of Notch activity ${ }^{[154]}$. Therefore, CCM proteins are involved in appropriate valve development ${ }^{[155]}$.

\section{CCM2 and ССM3 function coordinately in gonadogenesis}

$\mathrm{Ccm} 2$ and $\mathrm{Ccm} 3$ gene expressions are upregulated in adult mouse testis and ovaries, correlating with $\mathrm{CCM} 2$ and $\mathrm{CCM} 3$ protein expression, suggesting the involvement of $\mathrm{Ccm} 2$ and $\mathrm{Ccm} 3$ in the regulation of gonadogenesis. The expression pattern of CCM2 changes through embryogenesis. In the prenatal testis stage, $\mathrm{CCM} 2$ is mainly expressed in the interstitial cells of Leydig with little expression in gonocytes. Throughout gonad maturation, CCM2 begins to be expressed in spermatocytes, followed by the expression of CCM3. In ovaries, $\mathrm{CCM} 2$ is found in the oocyte nucleus at birth. Overtime this expression is decreased while the expression of CCM2 is increased in adult granulosa cells. The CCM2 in granulosa cells is expressed solely in the cytoplasm based on the spatiotemporally differential expression patterns of CCM2 and CCM3 in the testis and ovaries; it is plausible that CCM2 and CCM3 proteins may have different physiological roles during testicular and ovarian development ${ }^{[156]}$. Homozygous $\mathrm{C} \mathrm{cm} 3$ mutants in a C. elegans model rendered them sterile. These Ccm3 mutant worms had multinucleated germ cells that showed hypoproliferation, which may be caused by altered expression of Rab-11. Ccm3 promotes endocytic recycling by interacting with Rab-11. Defective endocytic recycling could result in decreased expression of Glp-1, a mediator of Notch signaling, and Rme-2, a mediator of protein endocytosis. Ccm3 deficient germ cells have defective late-stages of cytokinesis leading to multinucleate giant cells. Polarity of $C$. elegans is modulated by nonmuscle myosin ${ }^{[157]}$, while non-muscle myosin distribution is regulated by $\mathrm{Ccm} 3$. Ccm3-null embryos have aberrant expression of Par- 6 and Par-2, both of which are polarity proteins. Therefore, it can be concluded that embryonic polarity is mediated by $\mathrm{Ccm}^{[158]}$.

\section{CCM2 plays a role in the cardiac phenotype seen in CCM}

As we described before, CCM2 binds to MEKK3 through the HH domain, leading to increased expression in $\mathrm{KLF} 2, \mathrm{KLF} 4, \mathrm{ADAMTS} 4$, and ADAMTS $5^{[115]}$. These expression changes can be detected in the earliest stage of CCM lesions. The increased KLF4 and KLF2 were not only found in CCM lesions but also blood vessels in the cerebellum in $\mathrm{Ccm} 1$ knockout mice. These increased expressions were also reported in both sporadic and familial forms of human CCMs. Also, their early presence suggests that KLF4/KLF2 may be involved in the formation of lesions. MEKK3 is a MAP3 kinase that controls KLF2/KLF4 activity which is especially critical in cardiogenesis. Ccm1 null mutant mouse model is embryonic lethal, but Map3k3 haploinsufficiency is able to rescue this lethality. To determine the temporality of the Rho activation $v s$. MEKK3 activation, CCM1 depleted EC cells treated with hydroxyfasudil (a Rho inhibitor) was unable to normalize the levels of KLF4/ KLF2 while normalized KLF4/KLF2 levels in CCM1 null cells resulted in normal level of Rho activation, 
suggesting that the KLF4/KLF2 signaling is upstream of the Rho activation in CCM lesions ${ }^{[00]}$. Increased KLF4/KLF2 expression can lead to increased ADAMTS that functions to cleave proteoglycan matrix such as versican. Therefore, the up-regulation of ADAMTS can lead to disruption of intervening parenchyma around the blood vessel resulting in the formation of a cavernoma ${ }^{[12,13]}$.

\section{CCM3 is a regulator of cell apoptosis}

CCM3 has been linked to both apoptosis and cell survival pathways. Initially, CCM3 was discovered as a protein for granulocyte apoptosis. One proposed mechanism is that CCM3 binds with VEGFR2 resulting in increased stabilization of the receptor. Decreased CCM3 results in increased degradation of VEGFR2 leading to decreased VEGF stimulation ${ }^{[135]}$. Furthermore, CCM3 is implicated in translocation of MST4 to the periphery of the cell where it activates ERM proteins. These ERM proteins are anti-oxidative and thereby prolong cell survival ${ }^{[159]}$.

\section{CCM3 plays a role in exocytosis}

$\mathrm{CCM} 3$ is known to interact with STK24 and $\mathrm{UNC} 13 \mathrm{D}$, a known vesicle fusion regulator, in neutrophils. STK24 is an inhibitor of neutrophil vesicle exocytosis. STK24 deficient neutrophils release larger amounts of enzymes through exocytosis. STK24 localizes to neutrophil granules. There are two pools of granules in neutrophils: readily available and reserved. STK24 is associated with increased release of the reserved pool. UNC13D is a protein that binds to vesicles to promote their exocytosis. STK24 inhibits UNC13D ${ }^{[160,161]}$. CCM3 has a dual effect on neutrophil exocytosis. CCM3 binds to STK24 and stabilizes it to increase neutrophil exocytosis. However, CCM3 also increases the binding of $\mathrm{UNC13D}$ to liposomes through a calcium mediated mechanism, which is only seen in high intracellular concentrations. This inactivates excess UNC13D, resulting in decreased exocytosis. Simply stated, CCM3 is important for maintaining equilibrium of neutrophil exocytosis. Loss of CCM3 increases exocytosis of granules in neutrophils. This has been shown in renal ischemia-reperfusion injury model where reperfusion resulted in increased damage, suggesting that CCM3 deficiency results in an increased oxidative damage due to neutrophil exocytosis ${ }^{[162]}$.

CCM3 controls EC proliferation. Weibel-Palade bodies are granules in EC cells that contain angiopoietin-2 $(\mathrm{ANGPT} 2)^{[163,164]}$. ANGPT2 binds to a tyrosine kinase receptor, TIE-2, and regulates the formation of EC cell-cell junction in angiogenesis. Ccm 3 knockout mice were shown to have increased Angpt2 expression. Furthermore, TIE-2 showed more phosphorylation in areas such as cerebellum and retina, areas classically known to form CCM lesions. As explained previously, CCM3 is a mediator of exocytosis in neutrophils through UNC13B. It was seen to mediate exocytosis in EC as well. EC cells were shown to have increased exocytosis of granules which can be rescued by the suppression of UNK13B. ANGPT2 transcription or translation was not affected by $\mathrm{CCM} 3$ silencing, suggesting that this is not regulated at the transcriptional level. This is consistent with the theory that CCM3 blocks of exocytosis of ANGPT2. A decreased CCM lesion burden was observed in $\mathrm{Ccm} 3$ knockout mice with the introduction of ANGPT2 antibodies, reaffirming the involvement of TIE2 signaling in the CCM lesion formation. This finding provides another venue for potential pharmacotherapy ${ }^{[00]}$.

\section{CCM3 might have multiple cellular functions through its partners}

CCM3 interacts with STK25 or MST4 to form the STRIPAK complex ${ }^{[165]}$ which localizes to the cis-face of the Golgi complex ${ }^{[6]}$. At this location, it plays a role in appropriate positioning of the Golgi. GCKIII kinases are activated by homodimerization and resulting in its autophosphorylation, but activation is tightly regulated by $\mathrm{CCM}^{395]}$. Dysfunction of $\mathrm{CCM}_{3}$ results in the malposition of Golgi complex and centrosome $^{[166]}$. Migration is essential for proper placement of EC cells during angiogenesis. Increased expression of CCM3 causes over migration of EC cell ${ }^{[162]}$. Therefore, dysfunction of this process could be involved in the formation of CCM lesions. 


\section{CCM3 stabilizes intracellular bridges}

Certain cells such as germ cells have cytoplasmic connections that regulate cell-cell communication and coordination. Anillin proteins such as ANI-1 and ANI-2 regulate the length of these projections. ANI-1 is known to decrease bridge length, while its antagonist, ANI-2, increases bridge length ${ }^{[167]}$. It was found that GCK-1 that is regulated by CCM3 binds to ANI-1. Therefore, deficiencies in CCM3 and GCK-1 result in a decrease in intracellular bridge size. This results in multiple histological defects in the gonads such as reduced distal arm length, rachis diameter, and brood size. Fluorescence imaging studies showed that $\mathrm{CCM} 3$ localizes to the bridges. Co-deletions of $\mathrm{CCM} 3 / \mathrm{GCK}-1$ and ANI-1 resulted in increased bridge number, suggesting a similar pathway between GCK-1/CCM3 and ANI-1. Non-muscle myosin II (NMMII) is responsible for constriction of bridges. However, unopposed activation of NMMII causes hyperconstriction and results in destabilization of bridges $^{[168]}$. CCM3/GCK1 deletion resulted in increased localization of NMMII to the intracellular bridges and ANI-1 binds to NMMII. Therefore, it was postulated that intracellular bridges is regulated by CCM3-GCKIANI-1- NMMII signaling cascade. Yet, co-deletion of these genes did not affect bridge size. Therefore, it is likely that GCK1/CCM3 affects intracellular bridges through other signaling pathways.

\section{CCM lesions have defective autophagy}

$\mathrm{CCM} 3$, along with $\mathrm{CCM} 1$ and $\mathrm{CCM} 2$, are involved in many signaling pathways that result in increased production of ROS: Sirt1/FoxO1, JNK/c-JUN, $\beta$-catenin, and TGF- $\beta$ pathways ${ }^{[146,169-171]}$. This oxidative stress will damage organelles in the cell. However, inadequate autophagy mechanisms hinder cell recovery ability leading to progression of disease. CCM lesions show defect in autophagy through increased activity of mTOR. Inhibitors of mTOR were shown to reverse the defect in autophagy suggesting that mTOR is involved in the process, which provides another set of pharmacotherapeutic agents in CCM.

\section{CCM lesions have differentially expressed miRNA}

The composition of micro RNAs (miRNAs) in CCM lesions was analyzed through an mRNA expression screen. These results were supported by RT-qPCR. Compared to normal controls, it was found that 10 miRNAs were upregulated and 42 miRNAs was downregulated in CCM lesions. A more stringent analysis showed 5 miRNAs that were very significantly downregulated. Using bioinformatics, potential binding mRNAs to these 5 miRNAs were identified. One of the miRNAs had a potential 981 binding partners. Several proteins already implicated in CCM lesions were found to be targets of these miRNAs including MLLT4, VEGFA, MAPK1, RAC1, RHOA, FOXO1, ENG, SMURF1, and HEYL ${ }^{[1783,99,106,126,139]}$. It was concluded that three miRNAs (let-7b-5p, miR-361-5p, and miR-370-3p) can potentially be involved in the pathogenesis of $\mathrm{CCM}^{[172]}$.

\section{ССМ3 was frequently implicated in tumorigenesis}

CCM3 was initially identified as a tumor-associated apoptotic protein ${ }^{[2]}$. Several cases of meningiomas have been reported in patients with dysfunctional CCM3, suggesting that $\mathrm{CCM} 3$ could potentially act as a tumor suppressor ${ }^{[31,173,174]}$. One report stated that $\mathrm{CCM}_{3}$ deficient EC cells can continuously proliferate in cell cultures. In fibroblasts, CCM3 deficient cells can grow several more generations before entering senescence, comparing to wild-type cells. This suggests that the depletion of CCM3 delays cell senescence. Gene enrichment analysis showed a decreased production of cytokines in CCM3 deficient EC cells. Cytokine production was not inducible with TNF- $\alpha$ in these cells. It was found that these cells have a defect in C/EBP $\beta$ activity. C/EBP $\beta$ expression was upregulated in CCM3 deficient cells, which delays the progression of cells into senescence. Therefore, the lack of $\mathrm{C} / \mathrm{EBP} \beta$ activity is the likely driven factor in delaying the cells into senescence. Gene enrichment analysis showed decreased expression level of lysosome gene set. Senescent cells have increased autophagy for unutilized organelles and $\mathrm{CCM}_{3}$ deficient cells do not show increased activity of autophagy. Growth of $\mathrm{CCM} 3$ depleted cells in minimum nutrient media showed impairment of autophagy. Therefore, CCM3 deficiency increases C/EBP $\beta$ activity that, in turn, impairs cell senescence, resulting in declined cellular autophagy ${ }^{[175]}$. More research is needed to elucidate the underlined relationship between CCM3-mediated senescence and meningiomas. 
Interactome
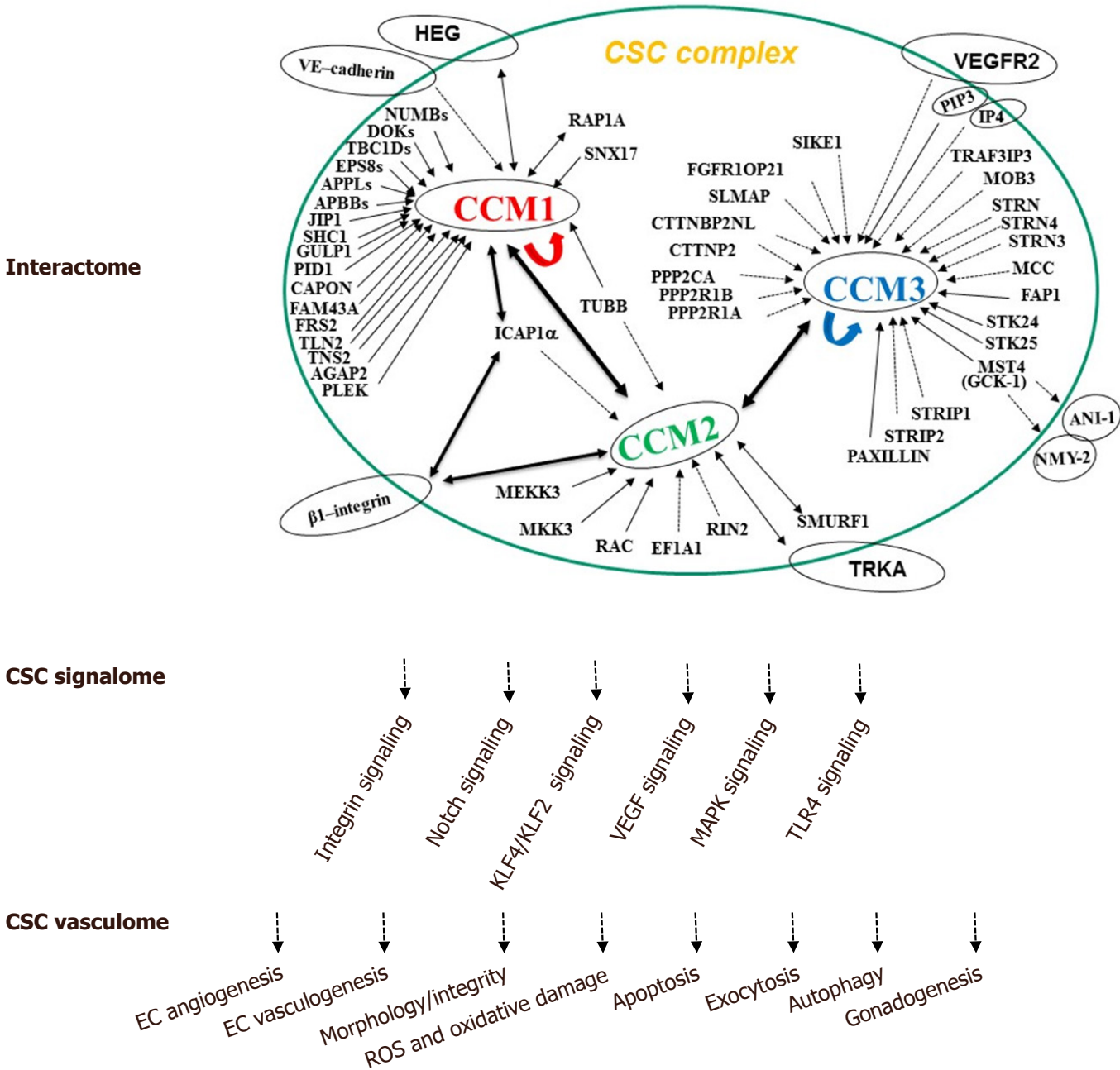

Figure 1. The cellular roles of the CSC complex. The schematic diagram summarizes the known CSC interaction protein partners (interactome), defined CSC-modulated signaling pathways (signalome), and distinct molecular and cellular functions of CSC complex (vasculome) with our current understanding of CSC cellular functions. CCM: cerebral cavernous malformations; CSC: CCM signaling complex; EC: endothelial cells

CCM3 mRNA 3'UTR was found to be able to bind to Mir-103, a microRNA that was found to be associated with prostate cancer. This microRNA was found to be down-regulated in prostate cancer. Furthermore, in vivo studies showed that up-regulation of Mir-103 restored cells to senescence. The in vitro studies of cell culture showed that Mir-103 plays an important role for G1/S cellular checkpoint. When Mir-103 binds to CCM3 mRNA, it targets the CCM3 transcript for degradation. The decreased expression of CCM3 in the cell leads to increased apoptosis. Further, overexpression Mir-103 in normal cells resulted in increased apoptosis. Likewise, down-regulation of $\mathrm{CCM} 3$ observed in a prostate cancer cell line resulted in increased apoptosis ${ }^{[176]}$, suggesting that $\mathrm{CCM} 3$ may play a role as oncogene or tumor suppressor (depending on cell signaling), in the tumorigenesis.

In summary, CCM proteins form a signaling complex (CSC) that have been demonstrated to play major roles in the regulation of multiple cell structures and signaling mechanisms involved in fundamental physiological and biogenic functions, as well as in cell responses to various environmental stressors. We have detailed these recent findings in the review, with a diagrammatic summary of major functions of CSC in three categories: interactome, signalome, and vasculome [Figure 1]. 


\section{DECLARATIONS}

\section{Author's contributions}

Akhil Padarti drafted the manuscript under the supervision of Jun Zhang.

\section{Availability of data and materials}

Not applicable.

\section{Financial support and sponsorship}

R21 NS061191/NS/NINDS NIH HHS/United States.

\section{Conflicts of interest}

Both authors declared that there are no conflicts of interest.

\section{Ethical approval and consent to participate}

Not applicable.

\section{Consent for publication}

Not applicable.

\section{Copyright}

(c) The Author(s) 2018.

\section{REFERENCES}

1. Otten P, Pizzolato GP, Rilliet B, Berney J. 131 cases of cavernous angioma (cavernomas) of the CNS, discovered by retrospective analysis of 24,535 autopsies. Neurochirurgie 1989;35:82-3, 128-31.

2. Cavalcanti DD, Kalani MY, Martirosyan NL, Eales J, Spetzler RF, Preul MC. Cerebral cavernous malformations: from genes to proteins to disease. J Neurosurg 2012;116:122-32.

3. Fisher OS, Zhang R, Li X, Murphy JW, Demeler B, Boggon TJ. Structural studies of cerebral cavernous malformations 2 (CCM2) reveal a folded helical domain at its C-terminus. FEBS Lett 2013;587:272-7.

4. Tanriover G, Sozen B, Seker A, Kilic T, Gunel M, Demir N. Ultrastructural analysis of vascular features in cerebral cavernous malformations. Clin Neurol Neurosurg 2013;115:438-44.

5. Choquet H, Trapani E, Goitre L, Trabalzini L, Akers A, Fontanella M, et al. Cytochrome P450 and matrix metalloproteinase genetic modifiers of disease severity in Cerebral Cavernous Malformation type 1. Free Radic Biol Med 2016;92:100-9.

6. Trapani E, Retta SF. Cerebral cavernous malformation (CCM) disease: from monogenic forms to genetic susceptibility factors. J Neurosurg Sci 2015;59:201-9.

7. Gunel M, Awad IA, Finberg K, Anson JA, Steinberg GK, Batjer HH, Kopitnik TA, Morrison L, Giannotta SL, Nelson-Williams C, Lifton RP. A founder mutation as a cause of cerebral cavernous malformation in Hispanic Americans. N Engl J Med 1996;334:946-51.

8. Denier C, Labauge P, Bergametti F, Marchelli F, Riant F, Arnoult M, Maciazek J, Vicaut E, Brunereau L, Tournier-Lasserve E; Société Française de Neurochirurgie. Genotype-phenotype correlations in cerebral cavernous malformations patients. Ann Neurol 2006;60:550-6.

9. Liquori CL, Berg MJ, Squitieri F, Ottenbacher M, Sorlie M, Leedom TP, Cannella M, Maglione V, Ptacek L, Johnson EW, Marchuk DA. Low frequency of PDCD10 mutations in a panel of CCM3 probands: potential for a fourth CCM locus. Hum Mutat 2006;27:118.

10. Liquori CL, Penco S, Gault J, Leedom TP, Tassi L, Esposito T, Awad IA, Frati L, Johnson EW, Squitieri F, Marchuk DA, Gianfrancesco F. Different spectra of genomic deletions within the CCM genes between Italian and American CCM patient cohorts. Neurogenetics 2008;9:25-31.

11. Scimone C, Bramanti P, Alafaci C, Granata F, Piva F, Rinaldi C, Donato L, Greco F, Sidoti A, D’Angelo R. Update on Novel CCM Gene Mutations in Patients with Cerebral Cavernous Malformations. J Mol Neurosci 2017;61:189-98.

12. Akers AL, Johnson E, Steinberg GK, Zabramski JM, Marchuk DA. Biallelic somatic and germline mutations in cerebral cavernous malformations (CCMs): evidence for a two-hit mechanism of CCM pathogenesis. Hum Mol Genet 2009;18:919-30.

13. Pagenstecher A, Stahl S, Sure U, Felbor U. A two-hit mechanism causes cerebral cavernous malformations: complete inactivation of CCM1, CCM2 or CCM3 in affected endothelial cells. Hum Mol Genet 2009;18:911-8.

14. Batra S, Lin D, Recinos PF, Zhang J, Rigamonti D. Cavernous malformations: natural history, diagnosis and treatment. Nat Rev Neurol 2009;5:659-70.

15. Zhang J, Basu S, Clatterbuck RE, Rigamonti D, Dietz HC. Pathogenesis of cerebral cavernous malformation: Depletion of Krit1 leads to perturbation of 1 integrin-mediated endothelial cell mobility and survival. Am J Hum Genet 2004;suppl:S222. 
16. Hilder TL, Malone MH, Bencharit S, Colicelli J, Haystead TA, Johnson GL, Wu CC. Proteomic identification of the cerebral cavernous malformation signaling complex. J Proteome Res 2007;6:4343-55.

17. Zawistowski JS, Stalheim L, Uhlik MT, Abell AN, Ancrile BB, Johnson GL, Marchuk DA. CCM1 and CCM2 protein interactions in cell signaling: implications for cerebral cavernous malformations pathogenesis. Hum Mol Genet 2005;14:2521-31.

18. Zhang J, Rigamonti D, Dietz HC, Clatterbuck RE. Interaction between krit1 and malcavernin: implications for the pathogenesis of cerebral cavernous malformations. Neurosurgery 2007;60:353-9; discussion 9.

19. Zhang J, Dubey P, Padarti A, Zhang A, Patel R, Patel V, Cistola D, Badr A. Novel functions of CCM1 delimit the relationship of PTB/ PH domains. Biochim Biophys Acta 2017;1865:1274-86.

20. Zhang J, Clatterbuck RE, Rigamonti D, Chang DD, Dietz HC. Interaction between krit1 and icap1alpha infers perturbation of integrin beta1-mediated angiogenesis in the pathogenesis of cerebral cavernous malformation. Hum Mol Genet 2001;10:2953-60.

21. Ma X, Zhao H, Shan J, Long F, Chen Y, Chen Y, Zhang Y, Han X, Ma D. PDCD10 interacts with Ste20-related kinase MST4 to promote cell growth and transformation via modulation of the ERK pathway. Mol Biol Cell 2007;18:1965-78.

22. Uhlik MT, Abell AN, Johnson NL, Sun W, Cuevas BD, Lobel-Rice KE, et al. Rac-MEKK3-MKK3 scaffolding for p38 MAPK activation during hyperosmotic shock. Nat Cell Biol 2003;5:1104-10.

23. Zhang J. Molecular biology of cerebral cavernous malformation. In: Rigamonti D, editor. Cavernous Malformations of the Nervous System. Cambridge: Cambridge University Press 2011 p. 31-40.

24. Zhang J, Basu S, Rigamonti D, Dietz HC, Clatterbuck RE. Depletion of KRIT1 leads to perturbation of beta 1 integrin-mediated endothelial cell angiogenesis in the pathogenesis of cerebral cavernous malformation. Stroke 2005;36:425.

25. Zhang J, Basu S, Rigamonti D, Dietz HC, Clatterbuck RE. Krit1 modulates beta 1-integrin-mediated endothelial cell proliferation. Neurosurgery 2008;63:571-8; discussion 8 .

26. Richardson BT, Dibble CF, Borikova AL, Johnson GL. Cerebral cavernous malformation is a vascular disease associated with activated RhoA signaling. Biol Chem 2013;394:35-42.

27. Labauge P, Enjolras O, Bonerandi JJ, Laberge S, Dandurand M, Joujoux JM, Tournier-Lasserve E. An association between autosomal dominant cerebral cavernomas and a distinctive hyperkeratotic cutaneous vascular malformation in 4 families. Ann Neurol 1999;45:250-4.

28. Gianfrancesco F, Cannella M, Martino T, Maglione V, Esposito T, Innocenzi G, Vitale E, Liquori CL, Marchuk DA, Squitieri F. Highly variable penetrance in subjects affected with cavernous cerebral angiomas (CCM) carrying novel CCM1 and CCM2 mutations. Am J Med Genet B Neuropsychiatr Genet 2007;144B:691-5.

29. Grippaudo FR, Piane M, Amoroso M, Longo B, Penco S, Chessa L, Giubettini M, Santanelli F. Cutaneous venous malformations related to KRIT1 mutation: case report and literature review. J Mol Neurosci 2013;51:442-5.

30. Toldo I, Drigo P, Mammi I, Marini V, Carollo C. Vertebral and spinal cavernous angiomas associated with familial cerebral cavernous malformation. Surg Neurol 2009;71:167-71.

31. Riant F, Bergametti F, Fournier HD, Chapon F, Michalak-Provost S, Cecillon M, Lejeune P, Hosseini H, Choe C, Orth M, Bernreuther C, Boulday G, Denier C, Labauge P, Tournier-Lasserve E. CCM3 Mutations Are Associated with Early-Onset Cerebral Hemorrhage and Multiple Meningiomas. Mol Syndromol 2013;4:165-72.

32. Nikoubashman O, Wiesmann M, Tournier-Lasserve E, Mankad K, Bourgeois M, Brunelle F, Sainte-Rose C, Wiesmann M, Zerah M, Di Rocco F. Natural history of cerebral dot-like cavernomas. Clin Radiol 2013;68:e453-9.

33. Fauth C, Rostasy K, Rath M, Gizewski E, Lederer AG, Sure U, et al. Highly variable intrafamilial manifestations of a CCM3 mutation ranging from acute childhood cerebral haemorrhage to late-onset meningiomas. Clin Neurol Neurosurg 2015;128:41-3.

34. Sirvente J, Enjolras O, Wassef M, Tournier-Lasserve E, Labauge P. Frequency and phenotypes of cutaneous vascular malformations in a consecutive series of 417 patients with familial cerebral cavernous malformations. J Eur Acad Dermatol Venereol 2009;23:1066-72.

35. Shenkar R, Shi C, Rebeiz T, Stockton RA, McDonald DA, Mikati AG, Zhang L, Austin C, Akers AL, Gallione CJ, Rorrer A, Gunel M, Min W, De Souza JM, Lee C, Marchuk DA, Awad IA. Exceptional aggressiveness of cerebral cavernous malformation disease associated with PDCD10 mutations. Genet Med. 2015;17(3):188-96.

36. Choquet H, Pawlikowska L, Lawton MT, Kim H. Genetics of cerebral cavernous malformations: current status and future prospects. J Neurosurg Sci 2015;59:211-20.

37. Rath M, Jenssen SE, Schwefel K, Spiegler S, Kleimeier D, Sperling C, Kaderali L, Felbor U. High-throughput sequencing of the entire genomic regions of CCM1/KRIT1, CCM2 and CCM3/PDCD10 to search for pathogenic deep-intronic splice mutations in cerebral cavernous malformations. Eur J Med Genet 2017;60:479-84.

38. Zhang J, Clatterbuck RE, Rigamonti D, Dietz HC. Mutations in KRIT1 in familial cerebral cavernous malformations. Neurosurgery 2000;46:1272-7; discussion 7-9.

39. Riant F, Bergametti F, Ayrignac X, Boulday G, Tournier-Lasserve E. Recent insights into cerebral cavernous malformations: the molecular genetics of CCM. FEBS J 2010;277:1070-5.

40. Haasdijk RA, Cheng C, Maat-Kievit AJ, Duckers HJ. Cerebral cavernous malformations: from molecular pathogenesis to genetic counselling and clinical management. Eur J Hum Genet 2012;20:134-40.

41. Petersen TA, Morrison LA, Schrader RM, Hart BL. Familial versus sporadic cavernous malformations: differences in developmental venous anomaly association and lesion phenotype. AJNR Am J Neuroradiol 2010;31:377-82.

42. Zhang J, Clatterbuck RE, Rigamonti D, Dietz HC. Cloning of the murine Krit1 cDNA reveals novel mammalian 5' coding exons. Genomics 2000;70:392-5.

43. Gingras AR, Puzon-McLaughlin W, Ginsberg MH. The structure of the ternary complex of Krev interaction trapped 1 (KRIT1) bound to both the Rap1 GTPase and the heart of glass (HEG1) cytoplasmic tail. J Biol Chem 2013;288:23639-49. 
44. Li X, Zhang R, Draheim KM, Liu W, Calderwood DA, Boggon TJ. Structural basis for small G protein effector interaction of Rasrelated protein 1 (Rap1) and adaptor protein Krev interaction trapped 1 (KRIT1). J Biol Chem 2012;287:22317-27.

45. Fisher OS, Boggon TJ. Signaling pathways and the cerebral cavernous malformations proteins: lessons from structural biology. Cell Mol Life Sci 2014;71:1881-92.

46. Faurobert E, Albiges-Rizo C. Recent insights into cerebral cavernous malformations: a complex jigsaw puzzle under construction. FEBS J. 2010;277:1084-96.

47. Francalanci F, Avolio M, De Luca E, Longo D, Menchise V, Guazzi P, et al. Structural and functional differences between KRIT1A and KRIT1B isoforms: a framework for understanding CCM pathogenesis. Exp Cell Res 2009;315:285-303.

48. Beraud-Dufour S, Gautier R, Albiges-Rizo C, Chardin P, Faurobert E. Krit 1 interactions with microtubules and membranes are regulated by Rap1 and integrin cytoplasmic domain associated protein-1. FEBS J 2007;274:5518-32.

49. Goult BT, Bate N, Anthis NJ, Wegener KL, Gingras AR, Patel B, Barsukov IL, Campbell ID, Roberts GC, Critchley DR. The structure of an interdomain complex that regulates talin activity. J Biol Chem 2009;284:15097-106.

50. Goult BT, Bouaouina M, Elliott PR, Bate N, Patel B, Gingras AR, Grossmann JG, Roberts GC, Calderwood DA, Critchley DR, Barsukov IL. Structure of a double ubiquitin-like domain in the talin head: a role in integrin activation. EMBO J 2010;29:1069-80.

51. Pecqueur L, Duellberg C, Dreier B, Jiang Q, Wang C, Plückthun A, Surrey T, Gigant B, Knossow M. A designed ankyrin repeat protein selected to bind to tubulin caps the microtubule plus end. Proc Natl Acad Sci U S A 2012;109:12011-6.

52. Zhang R, Li X, Boggon TJ. Structural analysis of the KRIT1 ankyrin repeat and FERM domains reveals a conformationally stable ARD-FERM interface. J Struct Biol 2015;192:449-56.

53. Bessman MJ, Frick DN, O'Handley SF. The MutT proteins or "Nudix" hydrolases, a family of versatile, widely distributed, "housecleaning" enzymes. J Biol Chem 1996;271:25059-62.

54. Liu W, Draheim KM, Zhang R, Calderwood DA, Boggon TJ. Mechanism for KRIT1 release of ICAP1-mediated suppression of integrin activation. Mol Cell 2013;49:719-29.

55. Petit N, Blecon A, Denier C, Tournier-Lasserve E. Patterns of expression of the three cerebral cavernous malformation (CCM) genes during embryonic and postnatal brain development. Gene Expr Patterns 2006;6:495-503.

56. Seker A, Pricola KL, Guclu B, Ozturk AK, Louvi A, Gunel M. CCM2 expression parallels that of CCM1. Stroke 2006;37:518-23.

57. Zhang J, Carr C, Badr A. The cardiovascular triad of dysfunctional angiogenesis. Transl Stroke Res 2011;2:339-45.

58. Stockton RA, Shenkar R, Awad IA, Ginsberg MH. Cerebral cavernous malformations proteins inhibit Rho kinase to stabilize vascular integrity. J Exp Med 2010;207:881-96.

59. Fisher OS, Liu W, Zhang R, Stiegler AL, Ghedia S, Weber JL, Boggon TJ. Structural basis for the disruption of the cerebral cavernous malformations 2 (CCM2) interaction with Krev interaction trapped 1 (KRIT1) by disease-associated mutations. J Biol Chem 2015;290:2842-53.

60. Scimone C, Bramanti P, Ruggeri A, Donato L, Alafaci C, Crisafulli C, Mucciardi M, Rinaldi C, Sidoti A, D’Angelo R. CCM3/ SERPINI1 bidirectional promoter variants in patients with cerebral cavernous malformations: a molecular and functional study. BMC Med Genet 2016;17:74.

61. Kean MJ, Ceccarelli DF, Goudreault M, Sanches M, Tate S, Larsen B, Gibson LC, Derry WB, Scott IC, Pelletier L, Baillie GS, Sicheri F, Gingras AC. Structure-function analysis of core STRIPAK Proteins: a signaling complex implicated in Golgi polarization. J Biol Chem. 2011;286(28):25065-75.

62. Dibble CF, Horst JA, Malone MH, Park K, Temple B, Cheeseman H, Barbaro JR, Johnson GL, Bencharit S. Defining the functional domain of programmed cell death 10 through its interactions with phosphatidylinositol-3,4,5-trisphosphate. PLoS One. 2010;5:e11740.

63. Li X, Zhang R, Zhang H, He Y, Ji W, Min W, Boggon TJ. Crystal structure of CCM3, a cerebral cavernous malformation protein critical for vascular integrity. J Biol Chem. 2010;285:24099-107.

64. Lant B, Yu B, Goudreault M, Holmyard D, Knight JD, Xu P, Zhao L, Chin K, Wallace E, Zhen M, Gingras AC, Derry WB. CCM-3/ STRIPAK promotes seamless tube extension through endocytic recycling. Nat Commun 2015;6:6449.

65. Rehain-Bell K, Love A, Werner ME, MacLeod I, Yates JR, 3rd, Maddox AS. A Sterile 20 Family Kinase and Its Co-factor CCM-3 Regulate Contractile Ring Proteins on Germline Intercellular Bridges. Curr Biol 2017;27:860-7.

66. Berman JR, Kenyon C. Germ-cell loss extends C. elegans life span through regulation of DAF-16 by kri-1 and lipophilic-hormone signaling. Cell 2006;124:1055-68.

67. Guzeloglu-Kayisli O, Amankulor NM, Voorhees J, Luleci G, Lifton RP, Gunel M. KRIT1/cerebral cavernous malformation 1 protein localizes to vascular endothelium, astrocytes, and pyramidal cells of the adult human cerebral cortex. Neurosurgery 2004;54:943-9; discussion 9.

68. Zhang J, Clatterbuck RE, Rigamonti D, Chang DD, Dietz HC. Novel insights regarding the pathogenesis of cerebral cavernous malformation (CCM). American Journal of Human Genetics 2001;69:178.

69. Serebriiskii I, Estojak J, Sonoda G, Testa JR, Golemis EA. Association of Krev-1/rap1a with Krit1, a novel ankyrin repeat-containing protein encoded by a gene mapping to 7q21-22. Oncogene 1997;15:1043-9.

70. Frische EW, Zwartkruis FJ. Rap1, a mercenary among the Ras-like GTPases. Dev Biol 2010;340:1-9.

71. Liu JJ, Stockton RA, Gingras AR, Ablooglu AJ, Han J, Bobkov AA, Ginsberg MH. A mechanism of Rap1-induced stabilization of endothelial cell--cell junctions. Mol Biol Cell 2011;22:2509-19.

72. Liu H, Rigamonti D, Badr A, Zhang J. Ccm1 regulates microvascular morphogenesis during angiogenesis. J Vasc Res 2011;48:130-40.

73. Lakshmikanthan S, Sobczak M, Chun C, Henschel A, Dargatz J, Ramchandran R, Chrzanowska-Wodnicka M. Rap1 promotes VEGFR2 activation and angiogenesis by a mechanism involving integrin alphavbeta(3). Blood 2011;118:2015-26. 
74. Chrzanowska-Wodnicka M, White GC, 2nd, Quilliam LA, Whitehead KJ. Small GTPase Rap1 Is Essential for Mouse Development and Formation of Functional Vasculature. PLoS One 2015;10:e145689.

75. Hamada K, Shimizu T, Matsui T, Tsukita S, Hakoshima T. Structural basis of the membrane-targeting and unmasking mechanisms of the radixin FERM domain. EMBO J 2000;19:4449-62.

76. Gingras AR, Liu JJ, Ginsberg MH. Structural basis of the junctional anchorage of the cerebral cavernous malformations complex. J Cell Biol 2012;199:39-48.

77. Brütsch R, Liebler SS, Wüstehube J, Bartol A, Herberich SE, Adam MG, Telzerow A, Augustin HG, Fischer A. Integrin cytoplasmic domain-associated protein-1 attenuates sprouting angiogenesis. Circ Res 2010;107:592-601.

78. Fournier HN, Dupé-Manet S, Bouvard D, Luton F, Degani S, Block MR, Retta SF, Albiges-Rizo C. Nuclear translocation of integrin cytoplasmic domain-associated protein 1 stimulates cellular proliferation. Mol Biol Cell 2005;16:1859-71.

79. Calderwood DA, Fujioka Y, de Pereda JM, García-Alvarez B, Nakamoto T, Margolis B, McGlade CJ, Liddington RC, Ginsberg MH. Integrin beta cytoplasmic domain interactions with phosphotyrosine-binding domains: a structural prototype for diversity in integrin signaling. Proc Natl Acad Sci U S A 2003;100:2272-7.

80. Bouvard D, Aszodi A, Kostka G, Block MR, Albiges-Rizo C, Fassler R. Defective osteoblast function in ICAP-1-deficient mice. Development 2007;134:2615-25.

81. Brunner M, Millon-Frémillon A, Chevalier G, Nakchbandi IA, Mosher D, Block MR, Albigès-Rizo C, Bouvard D. Osteoblast mineralization requires beta1 integrin/ICAP-1-dependent fibronectin deposition. J Cell Biol 2011;194:307-22.

82. Liu W, Boggon TJ. Cocrystal structure of the ICAP1 PTB domain in complex with a KRIT1 peptide. Acta Crystallogr Sect F Struct Biol Cryst Commun 2013;69:494-8.

83. Draheim KM, Fisher OS, Boggon TJ, Calderwood DA. Cerebral cavernous malformation proteins at a glance. J Cell Sci 2014;127:701-7.

84. Stiegler AL, Zhang R, Liu W, Boggon TJ. Structural determinants for binding of sorting nexin 17 (SNX17) to the cytoplasmic adaptor protein Krev interaction trapped 1 (KRIT1). J Biol Chem 2014;289:25362-73.

85. Uhlik MT, Temple B, Bencharit S, Kimple AJ, Siderovski DP, Johnson GL. Structural and evolutionary division of phosphotyrosine binding (PTB) domains. J Mol Biol 2005;345:1-20.

86. Harel L, Costa B, Tcherpakov M, Zapatka M, Oberthuer A, Hansford LM, Vojvodic M, Levy Z, Chen ZY, Lee FS, Avigad S, Yaniv I, Shi L, Eils R, Fischer M, Brors B, Kaplan DR, Fainzilber M. CCM2 mediates death signaling by the TrkA receptor tyrosine kinase. Neuron 2009;63:585-91.

87. Costa B, Kean MJ, Ast V, Knight JD, Mett A, Levy Z, Ceccarelli DF, Badillo BG, Eils R, König R, Gingras AC, Fainzilber M. STK25 protein mediates TrkA and CCM2 protein-dependent death in pediatric tumor cells of neural origin. J Biol Chem 2012;287:29285-9.

88. Crose LE, Hilder TL, Sciaky N, Johnson GL. Cerebral cavernous malformation 2 protein promotes smad ubiquitin regulatory factor 1-mediated RhoA degradation in endothelial cells. J Biol Chem 2009;284:13301-5.

89. Whitehead KJ, Chan AC, Navankasattusas S, Koh W, London NR, Ling J, Mayo AH, Drakos SG, Jones CA, Zhu W, Marchuk DA, Davis GE, Li DY. The cerebral cavernous malformation signaling pathway promotes vascular integrity via Rho GTPases. Nat Med 2009; $15: 177-84$.

90. Zhou Z, Tang AT, Wong WY, Bamezai S, Goddard LM, Shenkar R, Zhou S, Yang J, Wright AC, Foley M, Arthur JS, Whitehead KJ, Awad IA, Li DY, Zheng X, Kahn ML. Cerebral cavernous malformations arise from endothelial gain of MEKK3-KLF2/4 signalling. Nature 2016;532:122-6.

91. Draheim KM, Li X, Zhang R, Fisher OS, Villari G, Boggon TJ, Calderwood DA. CCM2-CCM3 interaction stabilizes their protein expression and permits endothelial network formation. J Cell Biol 2015;208:987-1001.

92. Zheng X, Xu C, Smith AO, Stratman AN, Zou Z, Kleaveland B, Yuan L, Didiku C, Sen A, Liu X, Skuli N, Zaslavsky A, Chen M, Cheng L, Davis GE, Kahn ML. Dynamic regulation of the cerebral cavernous malformation pathway controls vascular stability and growth. Dev Cell 2012;23:342-55.

93. Rosen JN, Sogah VM, Ye LY, Mably JD. ccm2-like is required for cardiovascular development as a novel component of the Heg-CCM pathway. Dev Biol 2013;376:74-85.

94. Ceccarelli DF, Laister RC, Mulligan VK, Kean MJ, Goudreault M, Scott IC, Derry WB, Chakrabartty A, Gingras AC, Sicheri F. CCM3/ PDCD10 heterodimerizes with germinal center kinase III (GCKIII) proteins using a mechanism analogous to CCM3 homodimerization. J Biol Chem 2011;286:25056-64.

95. Xu X, Wang X, Zhang Y, Wang DC, Ding J. Structural basis for the unique heterodimeric assembly between cerebral cavernous malformation 3 and germinal center kinase III. Structure 2013;21:1059-66.

96. Ding J, Wang X, Li DF, Hu Y, Zhang Y, Wang DC. Crystal structure of human programmed cell death 10 complexed with inositol$(1,3,4,5)$-tetrakisphosphate: a novel adaptor protein involved in human cerebral cavernous malformation. Biochem Biophys Res Commun. 2010;399:587-92.

97. Voss K, Stahl S, Hogan BM, Reinders J, Schleider E, Schulte-Merker S, Felbor U. Functional analyses of human and zebrafish 18-amino acid in-frame deletion pave the way for domain mapping of the cerebral cavernous malformation 3 protein. Hum Mutat 2009;30:1003-11.

98. Ridley AJ, Hall A. The small GTP-binding protein rho regulates the assembly of focal adhesions and actin stress fibers in response to growth factors. Cell 1992;70:389-99.

99. Zheng X, Xu C, Di Lorenzo A, Kleaveland B, Zou Z, Seiler C, Chen M, Cheng L, Xiao J, He J, Pack MA, Sessa WC, Kahn ML. CCM3 signaling through sterile 20-like kinases plays an essential role during zebrafish cardiovascular development and cerebral cavernous malformations. J Clin Invest 2010;120:2795-804.

100. Chan AC, Drakos SG, Ruiz OE, Smith AC, Gibson CC, Ling J, Passi SF, Stratman AN, Sacharidou A, Revelo MP, Grossmann AH, 
Diakos NA, Davis GE, Metzstein MM, Whitehead KJ, Li DY. Mutations in 2 distinct genetic pathways result in cerebral cavernous malformations in mice. J Clin Invest 2011;121:1871-81.

101. McDonald DA, Shenkar R, Shi C, Stockton RA, Akers AL, Kucherlapati MH, Kucherlapati R, Brainer J, Ginsberg MH, Awad IA, Marchuk DA. A novel mouse model of cerebral cavernous malformations based on the two-hit mutation hypothesis recapitulates the human disease. Hum Mol Genet 2011;20:211-22.

102. Li X, Ji W, Zhang R, Folta-Stogniew E, Min W, Boggon TJ. Molecular recognition of leucine-aspartate repeat (LD) motifs by the focal adhesion targeting homology domain of cerebral cavernous malformation 3 (CCM3). J Biol Chem 2011;286:26138-47.

103. Lu TJ, Lai WY, Huang CY, Hsieh WJ, Yu JS, Hsieh YJ, Chang WT, Leu TH, Chang WC, Chuang WJ, Tang MJ, Chen TY, Lu TL, Lai MD. Inhibition of cell migration by autophosphorylated mammalian sterile 20-like kinase 3 (MST3) involves paxillin and proteintyrosine phosphatase-PEST. J Biol Chem 2006;281:38405-17.

104. Wüstehube J, Bartol A, Liebler SS, Brütsch R, Zhu Y, Felbor U, Sure U, Augustin HG, Fischer A. Cerebral cavernous malformation protein CCM1 inhibits sprouting angiogenesis by activating DELTA-NOTCH signaling. Proc Natl Acad Sci U S A 2010;107:12640-5.

105. Liu H, Rigamonti D, Badr A, Zhang J. Ccm1 assures microvascular integrity during angiogenesis. Transl Stroke Res 2010;1:146-53.

106. Goitre L, Balzac F, Degani S, Degan P, Marchi S, Pinton P, Retta SF. KRIT1 regulates the homeostasis of intracellular reactive oxygen species. PLoS One 2010;5:e11786.

107. Guazzi P, Goitre L, Ferro E, Cutano V, Martino C, Trabalzini L, Retta SF. Identification of the Kelch family protein Nd1-L as a novel molecular interactor of KRIT1. PLoS One 2012;7:e44705.

108. Kato Y, Kravchenko VV, Tapping RI, Han J, Ulevitch RJ, Lee JD. BMK1/ERK5 regulates serum-induced early gene expression through transcription factor MEF2C. EMBO J 1997;16:7054-66.

109. Sohn SJ, Li D, Lee LK, Winoto A. Transcriptional regulation of tissue-specific genes by the ERK5 mitogen-activated protein kinase. Mol Cell Biol 2005;25:8553-66.

110. Dekker RJ, van Soest S, Fontijn RD, Salamanca S, de Groot PG, VanBavel E, Pannekoek H, Horrevoets AJ. Prolonged fluid shear stress induces a distinct set of endothelial cell genes, most specifically lung Kruppel-like factor (KLF2). Blood 2002;100:1689-98.

111. Ohnesorge N, Viemann D, Schmidt N, Czymai T, Spiering D, Schmolke M, Ludwig S, Roth J, Goebeler M, Schmidt M. Erk5 activation elicits a vasoprotective endothelial phenotype via induction of Kruppel-like factor 4 (KLF4). J Biol Chem 2010;285:26199-210.

112. Komaravolu RK, Adam C, Moonen JR, Harmsen MC, Goebeler M, Schmidt M. Erk5 inhibits endothelial migration via KLF2dependent down-regulation of PAK1. Cardiovasc Res 2015;105:86-95.

113. Maddaluno L, Rudini N, Cuttano R, Bravi L, Giampietro C, Corada M, Ferrarini L, Orsenigo F, Papa E, Boulday G, Tournier-Lasserve E, Chapon F, Richichi C, Retta SF, Lampugnani MG, Dejana E. EndMT contributes to the onset and progression of cerebral cavernous malformations. Nature 2013;498:492-6.

114. Cuttano R, Rudini N, Bravi L, Corada M, Giampietro C, Papa E, Morini MF, Maddaluno L, Baeyens N, Adams RH, Jain MK, Owens GK, Schwartz M, Lampugnani MG, Dejana E. KLF4 is a key determinant in the development and progression of cerebral cavernous malformations. EMBO Mol Med 2016;8:6-24.

115. Zhou Z, Rawnsley DR, Goddard LM, Pan W, Cao XJ, Jakus Z, Zheng H, Yang J, Arthur JS, Whitehead KJ, Li D, Zhou B, Garcia BA, Zheng X, Kahn ML. The cerebral cavernous malformation pathway controls cardiac development via regulation of endocardial MEKK3 signaling and KLF expression. Dev Cell 2015;32:168-80.

116. Renz M, Otten C, Faurobert E, Rudolph F, Zhu Y, Boulday G, Duchene J, Mickoleit M, Dietrich AC, Ramspacher C, Steed E, ManetDupé S, Benz A, Hassel D, Vermot J, Huisken J, Tournier-Lasserve E, Felbor U, Sure U, Albiges-Rizo C, Abdelilah-Seyfried S. Regulation of beta1 integrin-Klf2-mediated angiogenesis by CCM proteins. Dev Cell 2015;32:181-90.

117. Zhang X, Lawler J. Thrombospondin-based antiangiogenic therapy. Microvasc Res 2007;74:90-9.

118. Lopez-Ramirez MA, Fonseca G, Zeineddine HA, Girard R, Moore T, Pham A, Cao Y, Shenkar R, de Kreuk BJ, Lagarrigue F, Lawler J, Glass CK, Awad IA, Ginsberg MH. Thrombospondin1 (TSP1) replacement prevents cerebral cavernous malformations. J Exp Med 2017;214:3331-46.

119. Draheim KM, Huet-Calderwood C, Simon B, Calderwood DA. Nuclear Localization of Integrin Cytoplasmic Domain-associated Protein-1 (ICAP1) Influences beta1 Integrin Activation and Recruits Krev/Interaction Trapped-1 (KRIT1) to the Nucleus. J Biol Chem 2017;292:1884-98.

120. Piedra J, Miravet S, Castaño J, Pálmer HG, Heisterkamp N, García de Herreros A, Duñach M. p120 Catenin-associated Fer and Fyn tyrosine kinases regulate beta-catenin Tyr-142 phosphorylation and beta-catenin-alpha-catenin Interaction. Mol Cell Biol 2003;23:2287-97.

121. Potter MD, Barbero S, Cheresh DA. Tyrosine phosphorylation of VE-cadherin prevents binding of p120- and beta-catenin and maintains the cellular mesenchymal state. J Biol Chem 2005;280:31906-12.

122. DiStefano PV, Kuebel JM, Sarelius IH, Glading AJ. KRIT1 protein depletion modifies endothelial cell behavior via increased vascular endothelial growth factor (VEGF) signaling. J Biol Chem 2014;289:33054-65.

123. Hilder TL, Malone MH, Johnson GL. Hyperosmotic induction of mitogen-activated protein kinase scaffolding. Methods Enzymol 2007;428:297-312.

124. Zhou X, Izumi Y, Burg MB, Ferraris JD. Rac1/osmosensing scaffold for MEKK3 contributes via phospholipase C-gamma1 to activation of the osmoprotective transcription factor NFAT5. Proc Natl Acad Sci U S A 2011;108:12155-60.

125. Louvi A, Chen L, Two AM, Zhang H, Min W, Gunel M. Loss of cerebral cavernous malformation 3 (Ccm3) in neuroglia leads to CCM and vascular pathology. Proc Natl Acad Sci U S A 2011;108:3737-42.

126. You C, Sandalcioglu IE, Dammann P, Felbor U, Sure U, Zhu Y. Loss of CCM3 impairs DLL4-Notch signalling: implication in endothelial angiogenesis and in inherited cerebral cavernous malformations. J Cell Mol Med 2013;17:407-18. 
127. Zhu Y, Wu Q, Fass M, Xu JF, You C, Müller O, Sandalcioglu IE, Zhang JM, Sure U. In vitro characterization of the angiogenic phenotype and genotype of the endothelia derived from sporadic cerebral cavernous malformations. Neurosurgery 2011;69:722-31; discussion 31-2.

128. Harrington LS, Sainson RC, Williams CK, Taylor JM, Shi W, Li JL, Harris AL. Regulation of multiple angiogenic pathways by Dl14 and Notch in human umbilical vein endothelial cells. Microvasc Res 2008;75:144-54.

129. Kume T. Novel insights into the differential functions of Notch ligands in vascular formation. J Angiogenes Res 2009;1:8.

130. Hellstrom M, Phng LK, Gerhardt H. VEGF and Notch signaling: the yin and yang of angiogenic sprouting. Cell Adh Migr 2007;1:133-6.

131. Bheeshmachar G, Purushotaman D, Sade H, Gunasekharan V, Rangarajan A, Sarin A. Evidence for a role for notch signaling in the cytokine-dependent survival of activated T cells. J Immunol 2006;177:5041-50.

132. Poltorak A, He X, Smirnova I, Liu MY, Van Huffel C, Du X, Birdwell D, Alejos E, Silva M, Galanos C, Freudenberg M, RicciardiCastagnoli P, Layton B, Beutler B. Defective LPS signaling in C3H/HeJ and C57BL/10ScCr mice: mutations in Tlr4 gene. Science 1998;282:2085-8.

133. Huang Q, Yang J, Lin Y, Walker C, Cheng J, Liu ZG, Su B. Differential regulation of interleukin 1 receptor and Toll-like receptor signaling by MEKK3. Nat Immunol 2004;5:98-103.

134. Tang AT, Choi JP, Kotzin JJ, Yang Y, Hong CC, Hobson N, Girard R, Zeineddine HA, Lightle R, Moore T, Cao Y, Shenkar R, Chen M, Mericko P, Yang J, Li L, Tanes C, Kobuley D, Võsa U, Whitehead KJ, Li DY, Franke L, Hart B, Schwaninger M, Henao-Mejia J, Morrison L, Kim H, Awad IA, Zheng X, Kahn ML. Endothelial TLR4 and the microbiome drive cerebral cavernous malformations. Nature 2017;545:305-10.

135. He Y, Zhang H, Yu L, Gunel M, Boggon TJ, Chen H, Min W. Stabilization of VEGFR2 signaling by cerebral cavernous malformation 3 is critical for vascular development. Sci Signal 2010;3:ra26.

136. Fischer A, Zalvide J, Faurobert E, Albiges-Rizo C, Tournier-Lasserve E. Cerebral cavernous malformations: from CCM genes to endothelial cell homeostasis. Trends Mol Med 2013;19:302-8.

137. Herberich SE, Klose R, Moll I, Yang WJ, Wustehube-Lausch J, Fischer A. ANKS1B Interacts with the Cerebral Cavernous Malformation Protein-1 and Controls Endothelial Permeability but Not Sprouting Angiogenesis. PLoS One 2015;10:e0145304.

138. Vestweber D, Winderlich M, Cagna G, Nottebaum AF. Cell adhesion dynamics at endothelial junctions: VE-cadherin as a major player. Trends Cell Biol 2009;19:8-15.

139. Glading A, Han J, Stockton RA, Ginsberg MH. KRIT-1/CCM1 is a Rap1 effector that regulates endothelial cell cell junctions. J Cell Biol 2007;179:247-54

140. Goitre L, DiStefano PV, Moglia A, Nobiletti N, Baldini E, Trabalzini L, Keubel J, Trapani E, Shuvaev VV, Muzykantov VR, Sarelius IH, Retta SF, Glading AJ. Up-regulation of NADPH oxidase-mediated redox signaling contributes to the loss of barrier function in KRIT1 deficient endothelium. Sci Rep 2017;7:8296.

141. Goitre L, De Luca E, Braggion S, Trapani E, Guglielmotto M, Biasi F, Forni M, Moglia A, Trabalzini L, Retta SF. KRIT1 loss of function causes a ROS-dependent upregulation of c-Jun. Free Radic Biol Med 2014;68:134-47.

142. Hsieh HL, Lin CC, Chan HJ, Yang CM, Yang CM. c-Src-dependent EGF receptor transactivation contributes to ET-1-induced COX-2 expression in brain microvascular endothelial cells. J Neuroinflammation 2012;9:152.

143. Corr M, Lerman I, Keubel JM, Ronacher L, Misra R, Lund F, Sarelius IH, Glading AJ. Decreased Krev interaction-trapped 1 expression leads to increased vascular permeability and modifies inflammatory responses in vivo. Arterioscler Thromb Vasc Biol 2012;32:2702-10.

144. Retta SF, Glading AJ. Oxidative stress and inflammation in cerebral cavernous malformation disease pathogenesis: Two sides of the same coin. Int J Biochem Cell Biol 2016;81:254-70.

145. Espinosa-Diez C, Miguel V, Mennerich D, Kietzmann T, Sánchez-Pérez P, Cadenas S, Lamas S. Antioxidant responses and cellular adjustments to oxidative stress. Redox Biol 2015;6:183-97.

146. Dodson M, Redmann M, Rajasekaran NS, Darley-Usmar V, Zhang J. KEAP1-NRF2 signalling and autophagy in protection against oxidative and reductive proteotoxicity. Biochem J 2015;469:347-55.

147. Siow RC, Mann GE. Dietary isoflavones and vascular protection: activation of cellular antioxidant defenses by SERMs or hormesis? Mol Aspects Med 2010;31:468-77.

148. Bryan HK, Olayanju A, Goldring CE, Park BK. The Nrf2 cell defence pathway: Keap1-dependent and -independent mechanisms of regulation. Biochem Pharmacol 2013;85:705-17.

149. Yuan X, Xu C, Pan Z, Keum YS, Kim JH, Shen G, Yu S, Oo KT, Ma J, Kong AN. Butylated hydroxyanisole regulates ARE-mediated gene expression via Nrf2 coupled with ERK and JNK signaling pathway in HepG2 cells. Mol Carcinog 2006;45:841-50.

150. Schalkwijk CG, van Bezu J, van der Schors RC, Uchida K, Stehouwer CD, van Hinsbergh VW. Heat-shock protein 27 is a major methylglyoxal-modified protein in endothelial cells. FEBS Lett 2006;580:1565-70.

151. Nomura W, Inoue Y. Methylglyoxal activates the target of rapamycin complex 2-protein kinase C signaling pathway in Saccharomyces cerevisiae. Mol Cell Biol 2015;35:1269-80.

152. Antognelli C, Trapani E, Delle Monache S, Perrelli A, Daga M, Pizzimenti S, Barrera G, Cassoni P, Angelucci A, Trabalzini L, Talesa VN, Goitre L, Retta SF. KRIT1 loss-of-function induces a chronic Nrf2-mediated adaptive homeostasis that sensitizes cells to oxidative stress: Implication for Cerebral Cavernous Malformation disease. Free Radic Biol Med 2018;115:202-18.

153. Munch J, Grivas D, Gonzalez-Rajal A, Torregrosa-Carrion R, de la Pompa JL. Notch signalling restricts inflammation and serpine1 expression in the dynamic endocardium of the regenerating zebrafish heart. Development 2017;144:1425-40.

154. Beis D, Bartman T, Jin SW, Scott IC, D’Amico LA, Ober EA, Verkade H, Frantsve J, Field HA, Wehman A, Baier H, Tallafuss A, BallyCuif L, Chen JN, Stainier DY, Jungblut B. Genetic and cellular analyses of zebrafish atrioventricular cushion and valve development. 
Development 2005;132:4193-204.

155. Donat S, Lourenco M, Paolini A, Otten C, Renz M, Abdelilah-Seyfried S. Heg 1 and Ccm1/2 proteins control endocardial mechanosensitivity during zebrafish valvulogenesis. Elife 2018;7: pii: e28939.

156. Yaba A, Ordueri NE, Tanriover G, Sahin P, Demir N, Celik-Ozenci C. Expression of CCM2 and CCM3 during mouse gonadogenesis. J Assist Reprod Genet 2015;32:1497-507.

157. Guo S, Kemphues KJ. A non-muscle myosin required for embryonic polarity in Caenorhabditis elegans. Nature 1996;382:455-8.

158. Pal S, Lant B, Yu B, Tian R, Tong J, Krieger JR, Moran MF, Gingras AC, Derry WB. CCM-3 Promotes C. elegans Germline Development by Regulating Vesicle Trafficking Cytokinesis and Polarity. Curr Biol 2017;27:868-76.

159. Fidalgo M, Guerrero A, Fraile M, Iglesias C, Pombo CM, Zalvide J. Adaptor protein cerebral cavernous malformation 3 (CCM3) mediates phosphorylation of the cytoskeletal proteins ezrin/radixin/moesin by mammalian Ste20-4 to protect cells from oxidative stress. J Biol Chem 2012;287:11556-65.

160. Pivot-Pajot C, Varoqueaux F, de Saint Basile G, Bourgoin SG. Munc13-4 regulates granule secretion in human neutrophils. J Immunol 2008;180:6786-97.

161. Boswell KL, James DJ, Esquibel JM, Bruinsma S, Shirakawa R, Horiuchi H, Martin TF. Munc13-4 reconstitutes calcium-dependent SNARE-mediated membrane fusion. J Cell Biol 2012;197:301-12.

162. Zhang M, Dong L, Shi Z, Jiao S, Zhang Z, Zhang W, Liu G, Chen C, Feng M, Hao Q, Wang W, Yin M, Zhao Y, Zhang L, Zhou Z. Structural mechanism of CCM3 heterodimerization with GCKIII kinases. Structure 2013;21:680-8.

163. Fiedler U, Reiss Y, Scharpfenecker M, Grunow V, Koidl S, Thurston G, Gale NW, Witzenrath M, Rosseau S, Suttorp N, Sobke A, Herrmann M, Preissner KT, Vajkoczy P, Augustin HG. Angiopoietin-2 sensitizes endothelial cells to TNF-alpha and has a crucial role in the induction of inflammation. Nat Med 2006;12:235-9.

164. Lowenstein CJ, Morrell CN, Yamakuchi M. Regulation of Weibel-Palade body exocytosis. Trends Cardiovasc Med 2005;15:302-8.

165. Sugden PH, McGuffin LJ, Clerk A. SOcK, MiSTs, MASK and STicKs: the GCKIII (germinal centre kinase III) kinases and their heterologous protein-protein interactions. Biochem J 2013;454:13-30.

166. Fidalgo M, Fraile M, Pires A, Force T, Pombo C, Zalvide J. CCM3/PDCD10 stabilizes GCKIII proteins to promote Golgi assembly and cell orientation. J Cell Sci 2010;123:1274-84.

167. Maddox AS, Habermann B, Desai A, Oegema K. Distinct roles for two C. elegans anillins in the gonad and early embryo. Development 2005; $132: 2837-48$.

168. Yamamoto S, Bayat V, Bellen HJ, Tan C. Protein phosphatase 1ss limits ring canal constriction during Drosophila germline cyst formation. PLoS One 2013;8:e70502.

169. Marchi S, Corricelli M, Trapani E, Bravi L, Pittaro A, Delle Monache S, Ferroni L, Patergnani S, Missiroli S, Goitre L, Trabalzini L, Rimessi A, Giorgi C, Zavan B, Cassoni P, Dejana E, Retta SF, Pinton P. Defective autophagy is a key feature of cerebral cavernous malformations. EMBO Mol Med 2015;7:1403-17.

170. Yogev O, Shaulian E. Jun proteins inhibit autophagy and induce cell death. Autophagy 2010;6:566-7.

171. Liu J, Bi X, Chen T, Zhang Q, Wang SX, Chiu JJ, Liu GS, Zhang Y, Bu P, Jiang F. Shear stress regulates endothelial cell autophagy via redox regulation and Sirt1 expression. Cell Death Dis 2015;6:e1827.

172. Kar S, Bali KK, Baisantry A, Geffers R, Samii A, Bertalanffy H. Genome-Wide Sequencing Reveals MicroRNAs Downregulated in Cerebral Cavernous Malformations. J Mol Neurosci. 2017;61:178-88.

173. Clark VE, Erson-Omay EZ, Serin A, Yin J, Cotney J, Ozduman K, Avşar T, Li J, Murray PB, Henegariu O, Yilmaz S, Günel JM, Carrión-Grant G, Yilmaz B, Grady C, Tanrikulu B, Bakircioğlu M, Kaymakçalan H, Caglayan AO, Sencar L, Ceyhun E, Atik AF, Bayri Y, Bai H, Kolb LE, Hebert RM, Omay SB, Mishra-Gorur K, Choi M, Overton JD, Holland EC, Mane S, State MW, Bilgüvar K, Baehring JM, Gutin PH, Piepmeier JM, Vortmeyer A, Brennan CW, Pamir MN, Kiliç T, Lifton RP, Noonan JP, Yasuno K, Günel M. Genomic analysis of non-NF2 meningiomas reveals mutations in TRAF7, KLF4, AKT1, and SMO. Science 2013;339:1077-80.

174. Labauge P, Fontaine B, Neau JP, Bergametti F, Riant F, Blecon A, Marchelli F, Arnoult M, Lannuzel A, Clanet M, Olschwang S, Denier C, Tournier-Lasserve E. Multiple dural lesions mimicking meningiomas in patients with CCM3/PDCD10 mutations. Neurology 2009;72:2044-6.

175. Guerrero A, Iglesias C, Raguz S, Floridia E, Gil J, Pombo CM, Zalvide J. The cerebral cavernous malformation 3 gene is necessary for senescence induction. Aging Cell 2015;14:274-83.

176. Fu X, Zhang W, Su Y, Lu L, Wang D, Wang H. MicroRNA-103 suppresses tumor cell proliferation by targeting PDCD10 in prostate cancer. Prostate 2016;76:543-51. 